\title{
Impact of One Stop Shops on Consumer Buying Pattern
}

\author{
Baseera Hashmi \\ Department of Commerce, Jinnah University for Women \\ House \#34, Street \#7, Block H, Nazimabad \#3, City Karachi, Pakistan
}

\begin{abstract}
Supermarkets initially became famous in the 1950's when numerous staple shops progressed toward becoming 'self-benefit'. Until when shops at that point had all utilized the " over-the-counter strategy' of offering, where clients told a businessperson what they needed, and he/she got if off racking behind the counter. The new supermarkets used an open course of action design, which empowered customers to scrutinize along racking to pick stock for themselves. But increasing trend of one stop shop also created some negative outcomes by influencing consumer buying pattern. This quantitative research focused on finding the relationship between one independent variable one stop shop and 6 dependent variables inflation, impulse buying, Danger to health, Traffic jams, survival of small shops and rising property prices. The overall area target was one country i.e. Pakistan. The sample size selected from overall population was $n=200$. Primary data gathered here through questionnaires is based on both hardcopy and online survey forms. SPSS tool was used for data analysis. Findings proves that rising trend of one stop shops have a significant positive impact on economy and consumer buying pattern.
\end{abstract}

Keywords: Consumer Buying Pattern, inflation, impulse buying, Danger to health, Traffic jams, survival of small shops, rising property prices, one stop shops, Quantitative, Questionnaire, Supermarkets.

DOI: $10.7176 / \mathrm{JMCR} / 64-02$

Publication date: January $31^{\text {st }} 2020$

Chapter 01: Introduction

1. Introduction

1.1. One stop shop

A one-stop shop is an organization or an area that offers a large number of administrations to a customer or a client. The thought is to give advantageous and effective administration and furthermore to make the open door for the organization to pitch more items to customers and clients.

The business areas ordinarily are given by the dissemination centers of their parent associations, generally in the greatest city in the range. Markets typically offer things at for the most part low expenses by using their buying vitality to buy items from producers at cut down expenses than tinier stores can. They moreover restrict financing costs by paying for stock no less than thirty days after receipt and some focus credit terms of ninety days or more from merchants.

The market consistently incorporates flesh of animal, new convey, farm items, and warmed wares walkways, near to shelf space set something aside for tin packed and bundled things and furthermore for different non-sustenance things, for example, fundamentals for kitchen, household disinfectants, calm stock goods and pet items. A couple of markets also provide a combination of other household things that are exhausted reliably, for instance, alcohol (where permitted), pharmaceutical, and pieces of clothing and a couple of stores display a significantly broader extent of non-sustenance things: CDs, wielding equipment, prepackaged diversions, and infrequent things. The standard market includes a considerable measure of ground space, generally speaking on a singular level. It is typically orchestrated right around a neighborhood area with a particular ultimate objective to be beneficial to buyers. The basic intrigue is the openness of a wide assurance of items under a lone housetop. A greater full-advantage supermarket joined with a retail foundation is all over known as a hypermarket. Diverse organizations offered at a couple of stores may join those of banks, bistros, infant care centers/crèches, insurance (and other budgetary organizations), Mobile Phone organizations, photo getting ready, video rentals, medicate stores or possibly oil stations. If the burger joint in a general store is adequately huge, the workplace may be known as a "food merchant insect", a portmanteau of "essential need" and "restaurant".

\subsection{Background/History}

Grocery stores at first wound up plainly renowned in the nineteen fifties' the point at which various major shops advanced toward getting to be 'self-advantage'. Until the point when shops by then had all used the " over-thecounter system' of offering, where customers told a representative what they required, and he/she got if off racking behind the counter. The new supermarkets used an open course of action design, which empowered customers to scrutinize along racking to pick stock for themselves.

It was not until practically 10 years sometime subsequently Pakistan was profound of having its first strip 
plaza, when a shopping center with name Park Towers introduced in Karachi, with McDonald's getting first mover advantage and most perceptible label to expend retail room there. The plaza instantly changed into a public setting, where individuals went to be seen and value the civilities (a crystal holder lift and lifts were a peculiarity).

The introduction of Dolmen Mall on Tariq Road in two thousand, ended up being an unmistakable preferred standpoint. Dolmen Group's connected learning had influenced it to clear that the most ideal approach to deal with persuade the colossal names to continue board as inhabitants was to guarantee enough client improvement. All through the going with fifteen years, a development of shopping centers, for the most part in Karachi, including The Forum, Millennium Mall, Atrium Mall, The Ocean Mall and Tower and The Place came up, completely renaming the shopping establishment.

Today, most markets are controlled by national or multi-national retail chains. They pass on a broad assortment of strongly evaluated "have stamp" and checked stock.

There are distinctive markets continue running by think chains. These moreover started life in the late fifties when a couple of self-ruling essential supply shops comprehended that they couldn't battle with the tremendous market chains. They formed themselves into get-togethers and used their total vitality to mass buy at a refund from wholesalers. They were then prepared to pass on the discount to their customers. Regardless of the way that these shops use the name of the social event's chain and offer "claim stamp" stock they are not controlled by the chain. They are selective associations that are a bit of a total chain. They do this in light of the way that in case they endeavored to get by exclusively, the costs would be too high for them to battle with greater markets and they would leave business.

\subsection{One stop shops Merchandise}

Items available in large grocery stores provide variety of goods related to different label, bulk and assortments, including:

Playthings and peculiarities, Pet sustenance's and things, Meats, fish and sea sustenance's, Iced/ preserved foods and crushed ice, tobacco rolled in paper for smoking and other tobacco things (as country, state, typical or neighborhood laws allow), Publications, every day papers, and journals/papers, including supermarket tabloids, Personal use items for both men and ladies, Resident-cleaning things, Make-up kits, Food making ingredients and its preparation process utensils, Tablets, syrup, bandages etc. and restorative guide things (primarily completed the-counter solutions, but various markets moreover have an on area sedate store) (as laws allow), Tea and coffee (a couple of stores may have a business style processor, frequently open for self-advantage, or a staffed bistro that designs arranged to-drink coffee and tea refreshments), Financial organizations and things, for instance, contracts, Visas, financial balances, wire trades, et cetera (routinely offered in-store by a uniting bank or other cash related establishment), Alcoholic refreshments (as state, normal or adjacent laws allow), Farm items and eggs, Laundry things, for instance, chemicals and purging operators, Seasonal things and plans, PC items, music items and accounts (tallying video rentals), Baby sustenance's and newborn child mind things, for instance, unimportant diapers, Snack sustenance's, Personal cleanliness and preparing things, Breads and bread shop things (many stores may have a cake kitchen on area that offers distinguishing strength and treat things), All sorts of cards, Canned stock and dried grains, Bulk dried nourishment's, for instance, vegetables, flour, rice, et cetera (customarily open for self-advantage), Nonalcoholic refreshments, for instance, pop pops, presses, and separated water (a couple of stores may have a juice bar that prepares arranged to-drink freshly pulverized juices, smoothies, et cetera.), Condiment and Sauces, Luggage things (routinely obliged), Confectionery, Blooms, Delicatessen sustenance's (readied to-eat), Fresh results of the dirt, Housewares and dishware (routinely obliged),Diet sustenance's, Electrical things, for instance, lights, extra lines et cetera ready to cook food, Stationary etc.

\subsection{Supermarkets: Good or Bad?}

Grocery stores need to work with providers who are neighborhood and additionally far away. The need to supply great quality items at low costs implies that they can't work with agriculturists who don't create great quality items in extensive amounts. Their examination demonstrates that clients need gorgeous nourishment, not apples canvassed in scabs and wounds, so they don't stock sustenance that looks terrible. In the cutting-edge world there are different routes for little ranches to offer they create, similar to agriculturists markets and homestead shops. Because of this Shopping at markets is obliterating farming and demolishing the wide open. This power over the developed lifestyle empowers grocery stores to choose any amount of money they are willing to pay to agriculturists, due to no other supplier/buyer left in option or in the down the farmers are left with no choice to give the amount they set. Immense farmers are getting more noteworthy to survive while little agriculturists are getting to be plainly poverty stricken, and without job.

Shopping at large stores make hard the survival of small stores and it also neighborhood economies. Purchasers just pick or select the accessible great in suspected that might be on the off chance that they can avail 
those in general store; they won't get it in neighborhood shops in addition. That puts small shops and more dependable alternative stores insolvent. Every wide store that opens accomplishes a net loss of two hundred to three hundred occupations; general course of action of adjoining shops and their providers is pounded.

Mass transportation of items is the most reasonable strategy for moving things. A singular ship pile of bananas is more moderate to move than using twelve more diminutive water crafts. We see this all around us anyway it moreover pollutes the planet and damages human prosperity in light of the fact that the best single explanation behind an unnatural climate change is vehicle tainting. The ordinary thing of sustenance got from a general store goes more than one thousand miles; by air way from the creator to the store and after that by means of auto from the store to the customer. Also, moreover causing outrageous normal mischief, the tainting caused by showcase delivered action is an imperative supporter of rising levels of breathing problems and other breathing area diseases.

General stores are possessed by individuals who don't live locally, or even in a similar nation. The cash you spend there does not backpedal into the neighborhood economy, while cash spent in free shops tends to remain in the nearby economy. Since the grocery store HQ and managers live somewhere else, the cash goes somewhere else, into the financial balances of far off investors. Indeed, even the plastic packs are made in mass at focal areas, at times in entirely unexpected nations.

All around bundled items last more, are more secure to eat and look better. No body gripes about eggs being in egg boxes to secure them, so why whine about oranges being in a sack to keep them together, or bread being wrapped in plastic to keep germs and filthy fingers off it yet it really brings about absolutely pointless, earth dirtying and expensive bundling. Because of the immense separations that general store sustenance voyages, the time it takes to make that trip, and the requirement for the item to be stacked on a rack, and fitted with a scanner tag, grocery store nourishment is encased in much more bundling than is utilized by nearby generation and appropriation systems. Nourishment 'looks' must be saved so items are covered in plastic, pressed in water/air proof spreads, adhered to huge cardboard sheets to make dealing with less demanding, or advanced by being given splendid bundling.

General stores just have a high piece of the overall industry in light of the fact that their low costs drive other neighborhood shops bankrupt. In the event that there were more neighborhood shops and they weren't purposely undermined in cost by general stores, individuals would bolster nearby organizations.

On the off chance that stores didn't purchase from creating nations such places wouldn't have such vast homesteads or deliver the same number of yields. To state that the land would be utilized for nearby harvests and sustaining neighborhood individuals isn't generally genuine in light of the fact that to deliver the amounts of nourishment that store agriculturists do requires high innovation, water system and specific pressing and transporting that is the reason Shopping at grocery stores misuses both the general population and the place where there is creating nations. To minimize expenses and to expand benefits, general stores purchase the sustenance they offer from the creating scene where compensation are low, working conditions poor and contamination laws less strict or non-existent. This prompts nation beginning to rely upon remote purchasers for money and committing more land to trade crops.

Organizations say that Shopping at markets transforms suppers into energizing and advantageous encounters. Conventional shopping utilizing a few distinct shops to set up a solitary supper implied that customers needed to spend any longer discovering fixings. The fixings they found could change in quality from every day and customers were probably not going to be presented to new fixings or prepared cooked suppers. Time taken in social event fixings and making essential sustenance's was sat around idly. Purchasing a preinfluenced feast of known quality to can raise the eating background of a family while in genuine Shopping at general stores lessens suppers from being an essential and agreeable piece of life to a refueling exercise. The ceaseless need given to time-frame of realistic usability and consistency of size/shading/shape over taste has brought about market deliver being an insipid impersonation of what sustenance can and should possess a flavor like. What number of best culinary experts shop at grocery stores other than in the adverts?

Grocery store proprietors think Modern customers have occupied lives. They need to shop at advantageous areas and at helpful circumstances. Shops that shutdowns similarly as you leave work are no utilization to working individuals, and an ever-increasing number of couples now both work. Most dinners are anything but difficult to cook and you needn't bother with help or counsel, particularly if the general store has officially arranged the elements for you. You can simply choose a supper, take it home and eat it yet in genuine Modern customers aren't very different to customers of years prior. They need to purchase great items from a scope of very much evaluated things. They wouldn't fret going to master shops where retailers truly know their items. They like setting off to a butcher who can offer counsel on meat, a fishmonger who can filet the fish for you, and a greengrocer who can propose approaches to cook new vegetables. Home cooking is a family holding knowledge and can likewise bring about more beneficial dinners for the entire family. 


\subsection{Introduction}

All of us have gone to one stop shops, yet why do we go there? Alright, the conspicuous answer is 'to purchase things', however why do we go particularly to a grocery store instead of a nearby 'corner store' or elsewhere? Is it great that we go to a grocery store, or maybe we ought to be shopping somewhere else? The appropriate response most likely relies upon your identity and what you think about countless issues, for example, 'esteem for cash', 'comfort', 'reasonable exchange', 'sustenance quality', 'opportunity of decision' and so on.

There has been a lot of research in the showcasing field endeavoring to elucidate shopper practices as for expanding patterns of one stop markets or quick made of shopping centers.

Most advertisers have an entrenched diagram for customer travel conduct inside a grocery store- the normal client is expected to go here and there the passageways of the store, halting at different class areas, pondering about her thought set, picking the best (utility boosting) choice, and afterward proceeding in a comparative way until the point when the way is finished.

A few local retailers are utilizing their store design to boost incomes through Impulse purchases, for example, confectionery items are set at the main centers. Client behavior research uncover that this region is welcoming, and does not contain overwhelming presentations although it is the point where consumer or the shoppers frame an intuitive brand picture of the shop.

The area before the main centers is viewed as the most value maximization area. It contains the best items designed and settled with different offers. This is the reason pastry shop merchandise, meat, vegetables and staple things are normally put at an edge of these stores since they are vital purchases for clients. In the event that these item classifications are set close to the passage, consumer just enter in the grocery shop, pick up the items he she wanted, pays the bill and headed to home without have to look and be confused with other offers. In this manner, the idea is to plan the layout is that when clients achieve key purchases, they have quite recently been introduced to the most outrageous number of drive buys.

This implies situating infant items, for example, diapers, infant drain and adornments near beauty care products, design items and aromas as moms are the essential leaders in the purchase of these types of goods.

Next is the topic of optical promotion and items positioning in the shelf, both of which assume a key part in affecting purchasing designs. Surely famous brand always gets the place at the most lower or the upper racks since clients will invest additional energy and exertion searching for them. Introductory labels, on which huge amount of money is charged by the supplier get the place where buyers eye level is reached to guarantee more prominent perceivability and straightforward entry to instigate trial buying.

Families spend their money related plans in different ways along these lines will feel the impact of given esteem changes logically (or lower) than others. Family pay out plans - in this manner development experiences - could change proficiently transversely finished different social events. For instance, bring down wage pay families tend to spend a more noteworthy measure of their money related arrangement on sustenance, inferring that when food costs are increasing quickly, lower wage families face or experience generally above extension charges as compared to high pay ones.

Basic need charges say a great deal in regards to how purchasers and merchants carry on in an inflationary economy. Expansion never damages every person equally. Inflation is essentially an ascent in the normal cost of merchandise and enterprises in the large-scale economy.

Pricing is a standout amongst the most pivotal determinants of offers. Other than the genuine value, how the value offering is displayed to customers additionally influences purchaser assessment of the item advertising. The outcomes uncover many components that essentially impact recognize cut. For example, while both the percent of arrangement and the measure of arrangement decidedly impact recognized bargain investment funds, bargain percent has more effect.

Disregarding the way that purchaser perspective of value, money and standard are seen as most important topics of shopping behavior and thing choice (Doyle, Jacoby, Olson, Bishop, Sawyer, Dickson, Schlechter, 1984) additionally, these determinants may affect purchaser choice of general stores, in the meantime, here the request develop that what client mean by esteem, quality and cost?

If we see form the eye of consumer, amount charged have the capability to influence unintentionally to give up and purchase that item. This explanation is agreeable with (Ahtola's, 1984) dispute against including money related cost as a below level property in multi attribute chart since cost is a "give" section of the chart, rather than a "get" fragment. Portraying cost as surrender is consistent with conceptualizations by other assessing pros.

Quality is the term used as a piece of the writing to depict the genuine specific transcendence or eminence of the things. (e.g. Horthy-Anderson, 1984; Monroe and Krishnan, 1985).

Customer understanding of significant worth can be assembled as

1. Esteem is minimal effort (demonstrating that what they expected to surrender was most astounding in their perspective of critical worth),

2. Esteem is whatever I require in a thing, (the points of interest they got from the thing) particularly same as the business expert's importance of utility, 
3. Esteem is the quality I get at the cost I pay (exchange off between one "give" part, cost, and one "get" fragment),

4. Esteem is the thing that I get for what I give (all relevant "get" parts and moreover all applicable "give" fragments). As indicated by Pakistan Economic

Survey 2016-17 discount and Retail Trade development rate was 4.3 percent which is more than 2.3 percent (2015-16), discount and Retail Trade developed increased by 6.82 percent when contrasted with a year ago and discount and Retail Trade contribute 18.2 percent in Gross Domestic Product (GDP) and 18.3 percent (2015-16) that is there demonstrated some abatement of sectoral share in 2016-17 when contrasted with a year ago.

Amid the most recent twenty years, a scope of contrasting options to markets has created, including direct deals and conveyance plans. In any case, the greater part of this assortment is under danger from the forceful deals strategies of the huge grocery stores. Markets are presently concentrating on proceeding with development. They are planning to contend specifically with the whole scope of shops found in our towns and high lanes.

Grocery stores assert that they give decision to buyers; however, as a general rule they regularly dissolve genuine decisions for individuals. By overwhelming nourishment deals, they take away the decision to shop in conventional shops, they make it hard for new plans to begin and grow; and by focusing on non-sustenance shops they could take away the decision to visit a flourishing town focus.

Numerous superstores put resources into enhancing the store condition, made accessible all basic need, solidified things, general things, pharmaceutical, electronic and electrical things, sports, earthenware, quick nourishments, pastry shop things and numerous more to expand the assortment and to draw in more clients.

Store condition contains fusing parts, for example, space, smell, and music; design factors, for example, association and grouping; and social components, for example, the closeness and plentifulness of seller (Baker et al., 2002). Setup suggests the way in which things, buying wicker holder, and ways are ordered; the dimensions and state of things, and the relationship among them. Thing gathering are the aggregate course of action of things offered by a retailer. Social segments suggest the comprehensive group, for example, other customer and deals delegates (Baker et al., 2002).

Clients don't see a store in piecemeal edge and it is the aggregate arrangement of signs that influences their reactions (Wirtz, Mattila, 2001). Regardless, most earlier examinations don't operationalize store condition as a general make and rather investigate the impact of individual sections of store condition, for example, course of action and signage (Leong, Ang, Lim, 1997), thing amassing (Simonson, 1999), condition, and arrangements specialist accessibility, music (Dubé, Morin 2001, Beverland et al. 2006), and fragrance (Mattila, Wirtz, 2001, Chebat, Michon, 2003).

An examination report united by Deloitte and Planet Retail, The Path to 2020: Taking the Long View of Retail Market Entry, proposes something else. Of the aggregate basic supply retail deals in 2015, current basic need outlets addressed just $8.59 \%$ and projections for 2020 place this figure at an unessential $8.98 \%$, suggesting that the rule some portion of central supply getting $(91.02 \%)$ will even now be done at standard retail outlets?

According to an investigation look at coordinated by Standard Chartered Bank a year back, in the region of two thousand eleven and two thousand fifteen, the measure of the retail pie in Pakistan bounced from dollar ninety-six to one hundred and thirty-three billion, a 38.5\% extension in four years. The present estimation of Pakistan's retail division is evaluated to be dollar one hundred and fifty-two billion, as per Planet Retail (an overall retail consultancy) figures. It is the third greatest supporter of the economy (after agriculture and industry), speaks to $18 \%$ of the total GDP, and is the second greatest chief (in the wake of cultivating), offering occupations to more than $16 \%$ of the total work drive.

With a yearly improvement rate of $8 \%$, retail bargains are depended upon to cross the dollar two hundred million stamp before the complete of 2018. The standard factor filling this advancement, beside extending urbanization, is an improving work to-masses extent, which has provoked higher superfluous jobs, therefore developing the clerical class, which along these lines, has extended client spending complex (assessed at dollar two hundred and ninety-three million out of 2017 and foreseen to cross dollar three hundred and thirty-three million by 2018). This is chiefly in light of the fact that Pakistan has a young mass (more than $73 \%$ of the two hundred and twenty million tenants are underneath 35 years of age) that is upwardly adaptable, electronic informal communication watchful, stamp careful and cautious for quality things - and charming experiences.

This is likely why the (usually common) number of new small stores that have opened is less stood out from the advancement in the amount of general and retail chains, markets and hypermarkets, in the region of 2000 and 2016 (source: Retail Sector Report, Punjab Board of Investment and Trade). One possible reason is that youths rush to buy from street brokers, merchants and sellers, and lean toward current, objective arranged stores.

The country is drenched with superstores. At the present time is a perfect chance to consider the result of this settlement. The forces driving the stores to ever-fiercer competition and extending vertical concentration can similarly assemble social hardship and wreck the enabling structure of our adjacent food economies which keep up our market towns and towns, the sustenance creators who supply them and the overall public who depend upon them. There are buyers who exist past the rosy shimmer of the general store - the people who have no auto, 
who are not on the web, who live in a cash economy, whose shopping spending designs are too little to possess all the necessary qualities for home transports, who require their adjacent shop for social contact and exchange. For all intents and purposes all nourishment generation begins little scale and relies upon little retail outlets. At the point when superstores open, little shops close. Little shops, homesteads and sustenance organizations are related, giving work and purchaser decision. They are the premise of the rustic economy. The route forward is to guarantee we have the system set up that empowers the markets to coincide with the parallel coordinated neighborhood economy, instead of contend with it until the point when it is pulverized. Measure is essential to the entire issue. General stores that is improperly expansive for their catchment region without a doubt result in the conclusion of autonomous retailers.

It is a direct result of the development of grocery stores that nearby shops have shut, prompting the making of "sustenance deserts". Taking care of the issue is absolutely the obligation of various partners, including government and the police, not only the retailers. Arrangements ought to be made and legitimate moves ought to be made to guarantee that this proceeded with development isn't to the irreversible inconvenience of the neighborhood group. Current retailing strategy is driven to a great extent by the products. We have no general methodology for horticulture and retailing, however the two are reliant.

In spite of the plenitude, decision and accommodation of the store, nearby nourishment showcasing is one of the quickest developing developments in retailing, as we see from the fast extension of rancher's markets ( 0 to 250 of every three years). Retailing in the 21 st century must furnish the purchaser with the decision to shop outside the general store. The nearby nourishment economy is practical, it decreases sustenance miles, reduces auto utilize and it supports neighborhood recharging in both urban and provincial territories. Support ought to be given to neighborhood groups by guaranteeing the survival of nearby retailing however without denying buyers of the advantages of away shopping.

Grocery stores offer a considerable measure of item and they need to keep their items new for drawn out stretches of time, this implies they need to process their sustenance supply. Nourishment preparing is outstanding for effect sly affecting our wellbeing prompting heart issues, higher danger of tumor, more inclined to sicknesses and additionally essentially not getting as much sustenance out of what we eat.

The reason that stores are terrible for the earth is that as beforehand talked about they will by and large be worked in provincial rural areas which will then imply that autos will be required for individuals to contact them. Illicit stopping of autos, bicycles, vans, taxis, smaller than expected trucks and different vehicles have crumbled condition.

Colossal car influxes were seen in the zone after the outlets/grocery stores opening. Suburbanites were left stranded in the gridlock for quite a long time, leaving activity police powerless in clearing growl ups. The market is somewhat a bane for suburbanites as the excursion of a couple of minutes takes a few hours which tests their understanding under the singing sun. The nonappearance of appropriate and adequate stopping offices at the general store is the fundamental explanation for the turmoil (Pakistan today news, 2016.

The subject of how general stores influence the dynamic of an area has been dissected in various examinations in the past and showed up as often as possible all through prevalent media outlets.

Real media outlets have distributed a few articles talking about the gentrifying impact stores can have in neighborhoods following their opening (Cardwell, 2003).

People need to move to the range where they can accessible the best of openings for work. So, when greater part begins to move towards such ranges, a weight is based on such regions. This weight causes the ascent in the costs of property here. This marvel proceeds with; the proprietors of such properties get more certainty they contribute progressively and pull in the first run through purchasers. Thus, the economic situations turn out to be tight and general increment in the costs of land is watched. (Anderson, 2016)

Financial specialists get a kick out of the chance to contribute on the region which holds every one of the offices in itself, for instance office of power, landline, Sui gas, appropriate streets, water supply, grocery stores and business shops adjacent. With the expansion in high expectations for everyday comforts, individuals need to fit themselves in social orders giving most extreme utilities to its kin. (Anderson, 2016)

The main purpose of this research studies is to point out the drawbacks and after affects arising on the introduction of one stop shops which are playing a greater part in changing the consumer buying pattern, i.e. inflation, traffic blockages or jams, environmental, hygiene and health hazards, impulse buying, survival of small or local markets and grocery stores and so forth. After the identification and explanation of arising drawbacks the hypothesis will be tested to help explain the significance of these arising issues, whether they are harmful and should be removed or they only have a little effect and some remedies will solve the problem for that recommendations will be given as what remedies on public behalf have to be taken to minimize their effects and what steps government should take to drive those policies regarding the removal of one stop shops significant negative effect on economy. 


\subsection{Statement of Problem}

Amid the most recent twenty years, the scope of other options to grocery stores has created, including direct deals and conveyance plans. Be that as it may, the majority of this assortment is under danger from the forceful deals strategies of the huge markets. Grocery stores take away the decision to shop in conventional shops, and by focusing on non-food shops they could take away the decision to visit a flourishing town focus as a general rule they regularly disintegrate genuine decisions for individuals. One conceivable reason that makes survival of little stores troublesome is that youngsters are less quick to purchase from road shippers, merchants and peddlers, and incline toward present day, destination-oriented stores.

A few general stores are utilizing their store format to boost incomes through Impulse purchases; the key is to design formats such that when clients achieve strategic purchases, they have just been presented to the most extreme number of impulse purchases. Due to this now individuals are spending more than they save every month.

Supermarkets mostly follow packaging or discounting strategies often called pricing strategies which attract consumers to spend more and save less which push economy towards inflation.

Grocery stores, to keep their items fresh for longer period of time need to process their food supply which is notable for having unfavorable effect on our health prompting heart issues, higher danger of malignancy, more inclined to illnesses and additionally basically not getting as much sustenance out of what we eat.

General stores are terrible for wellbeing as well as to environment. They will mainly be constructed in country rural areas which will then imply that autos will be required for individuals to contact them. Illicit stopping of autos, bicycles, vans, taxis, small trucks and different vehicles have deteriorated environment.

The nonappearance of legitimate and adequate stopping facilities at the general store has also becomes the main reason behind the traffic jams. Suburbanites were left stranded in the gridlock for quite a long time, leaving activity police vulnerable in clearing snarl-ups.

With the expansion in high expectations for everyday comforts, individuals need to fit themselves in social orders/societies giving greatest utilities to its kin e: g electricity, landline, Sui gas, appropriate streets, water supply, general stores and business shops close-by. So, when larger part begins to move towards such zones, a weight is fabricated causing economic situations to end up plainly tight and general increment in the costs of land is watched.

\subsection{Research Questions}

i. Will you prefer to shop in large supermarket than a small kiryana store?

ii. If a product is out of stock in a supermarket would you search for it in other small stores or would you choose a substitute at any cost?

iii. Are you able to shop all the planned items on your grocery shopping list with in the superstore?

iv. Does shopping all monthly groceries at large supermarket let you save more?

v. Are you satisfied with the parking facility provided by superstores?

vi. Do you face traffic jams while travelling to or from a grocery store?

vii. What highlights do you search for shopping at a general store-i.e. price, quality of product, variety of product, branding etc.?

viii. Do you want that there should be more one stop shops in our country?

ix. Have you ever noticed or faced high property prices when a new store is open in that area?

$\mathrm{x}$. Does any time shopping at superstore in-shelf variety of impulse goods attract you to spend more?

xi. Which in your opinion is more favorable for health and also convenient to you, packed/frozen food or fresh items?

xii. Pre-prepared foods are very convenient, but if you know that they can be harmful for health will you still buy them?

\subsection{Research Objective}

i. To find the reasons behind heavy traffic jams occurring mainly near big grocery stores.

ii. To identify reasons behind increasing trend of packed and frozen food/vegetables/meat.

iii. To evaluate the impact of grocery stores on health.

iv. How supermarkets strategies are pushing economy towards inflation.

v. To identify basic reasons behind diminishing wealth of small stores.

vi. To decide whether and what premiums supermarkets are adding to homes and how these progressions when the distance between the home and the general stores changes.

vii. To analyze how Supermarkets, impact the shopping behaviors of most households.

viii. To characterize the ideas of value, quality, and incentive from the buyer's point of view.

ix. To know whether respondents are indiscreet purchaser or not with regards to purchasing basic need things. 
x. To analyze the impact of window display and limited time exercises on buyer motivation purchasing conduct.

\subsection{Scope of Research}

The measure of grocery store may fluctuate from mine to mega. The size is fundamentally impacted by the conditions in the region, purchasing example of the clients and the retail sprit winning in the range, for the most part the span of the general store in an area have a tendency to be all the more less to be the entirety the extent of the investigation has been confined to those departmental stores.

The examination concentrates on how purchasing behavior of purchaser can be influenced by one stop shops that is general stores, likewise their positive or negative effects on economy, for example, inflation, traffic blockages or jams, environmental, hygiene and health hazards, impulse buying, survival of small or local markets and grocery stores and so forth.

Stores increment simplicity of living as well as contribute in extravagant way of life as the grocery stores for the most part charged a lower cost for the items sold in light of the fact that the working costs all kept in the base. Subsequently a store is destined to the clients, since the costs are less expensive clients can be pulled in towards them. Subsequently they can have extensive and additionally quick turnover, these business sectors remain for comfort in shopping on the grounds that the clients can buy all their nourishment prerequisites immediately put. Close to the likewise have a wide assortment of things to choose. The clients are likewise given ideal opportunity to make their choice without the weight from the businessperson, then again, these stores are purposes behind numerous issues at the same time which are recorded above so for each simplicity there is dependably downsides. In more extensive point of view these downsides are making genuine harm to the economy and government ought to proficiently make compelling arrangements to adapt to the affect-ability of the circumstance.

The goal of this report is to feature the hazardous factor which is the reason of every such issue and furthermore discover the answers for manage those issues, objective is to support and help key players of public and private divisions of developing nations to find a way to unravel or to limit underneath literature demonstrated issues by taking appropriate measures, additionally this examination is a wellspring of data about buyer behavior in light of these effects and their motivation.

As indicated by "WALTLER AND PAUL" shopper conduct is the procedure whereby individual choose whether, what how and from when to buy merchandise and enterprises. Note that buyer conduct never stays settled yet it is consistently changing, different, for example, mental, practical and sociological components.

\section{Literature Review}

Introduction of one stop shops utilizing little to medium-estimate designs makes a focused danger for the current little stores, diminishing their likelihood of survival. The effect of general store passage is unequivocal for basic needs, pastry kitchens, crisp pasta shops, and butcher shops (Zipitría, L., Dubra, J., Ferrés, D., \& Borraz, F. (2014)).

United States has a background marked by the most grounded and longest hostile to general store administrative history of any nation on the planet (Wrigley and Lowe (2002)).

Over the most recent 30 years huge grocery stores had alteres the retail business scene in numerous nations through bigger store designs, more retire space, an expanded assortment of merchandise and enterprises and broad promoting procedures (Reardon and Hopkins (2006)).

The arrival of big stores builds market concentration in nearby markets i.e. the quantity of one stop shops and their shares of the aggregate generation (add up to limit or aggregate stores) in a market increases Franklin (2001).

These days, greater part of individuals give priority to utilize their private vehicles as opposed to public since they are more agreeable, speedier, more helpful and more adaptable for doing various undertakings on one outing (Downs, 2004). In numerous urban communities the significant retail ranges experience the ill effects of blockage because of a regularly expanding auto utilize. Congested urban system and urban stopping offices encompassing business ranges prompt a diminishing of availability for occupants, workers, clients and guests, and for administration and conveyance activity (Topp, 1991).

Pre-arranged/ half cooked nourishment's available at one stop shops are exceptionally advantageous, and can enable occupied individuals to set up a supper in substantially less time than it would take starting with no outside help. Illustrations can go from tinned or solidified vegetables, pre-hacked crisp vegetables, chilled side dishes, marinated meats, and finish solidified suppers, although it might have some side effects because of preservatives used in them which may have negative impacts on health. A home-cooked taste, the endorsement of other relatives, cost and soundness were impressively less imperative decisions for those shoppers. (Bird, Julia, 2016). Nutritional concerns are also of less significance to those individuals (Maibach, J, K, Glanz, M, Basil, E, Goldberg, D, Snyder, 1998). Processing of any sort additionally lessens the supplement content, and may even 
strip away those crucial cancer prevention agents that help insusceptible well-being and shield cells from harm (Overly, Jenny, 2014)

As the greater part of the general population wants to do shopping from grocery stores to deal with their chance adequately however for every comfort there are constantly a few downsides, for example, it makes motivation purchasing which cause increment sought after of most items that may prompt high costs and the result of this conditions is inflation. Controlling general inflation is an objective of monitory policy. Measures of in general, or feature, swelling endeavor to incorporate changes in the costs paid for a wide assortment of merchandise - that is, the thing that family units really need to pay for their everyday buys. This is a sensible idea of definitely what the national bank can and should control over the medium term. With treks to the service station and the supermarket being probably the most regular shopping encounters, it is not really accommodating for Fed believability to seem to avoid every one of those costs from thought in the arrangement of fiscal strategy (Federal Reserve Bank of St. Louis Review, 2011).

The unconstrained or spontaneous buy of products is the most ideal approach to characterize motivation purchasing. Motivation purchasing can occur in any item going from new item, tests to entrenched items with different rebate offers (Parboteeah, 2005) expressed that motivation obtaining is impromptu, the consequence of an introduction to a boost, and is chosen the-spot (Tinne, 2011). A client visits a store without having any expectation to purchase an item and accordingly get presented to specific jolts (can be inside boosts or outside) which triggers to purchase the item without scanning for data and choices. Along these lines, a purchaser moves toward becoming drive purchaser. On the premise of motivation buy, he/she will have certain experience be it positive or negative with the buy on drive. Motivation purchasing constitutes $27-62 \%$ of procurement of basic supply things (Rook, 1987). Buyer at market itself makes rash purchasing, between 50.8-67.7\% of aggregate buy (Economidates and Economidates, 2007). Mill (2002) and Mogelonsky (1998) in a report specified that buyers purchase hastily at some time and drive buys contribute a huge extent of the deals in stores (Sharma and Sivakumaran, 2014).

Utilization of unfortunate (vitality thick, supplement poor) nibble nourishments has turned out to be regular place in late decades. These utilization designs are probably going to be impacted by expanded chances to buy nibble sustenance's. In spite of the fact that the general store speaks to just a single nourishment shopping area, along these lines, the inside store grocery store condition is a critical point of convergence for general wellbeing sustenance explore. Inside markets, nibble sustenance's are frequently shown close to the passage and at checkouts and advancements related with such items are probably going to be normal. While earlier examinations have explored nibble sustenance shows at checkouts, a key in-store area where retailers endeavor to offer things liable to be bought on drive, these lone speak to a solitary purpose of introduction inside markets. Different shows, for example, those at the closures of paths and in island containers may likewise trigger an indiscreet decision before achieving the checkout (E., Cameron, A. J., McNaughton, S. Thornton, L., A., Worsley, A., \& Crawford, D. A. (2012)).

In spite the fact that, areas have a high predominance of little nourishment stores yet generally couple of markets as little sustenance stores are effectively available and as often as possible shopped at by neighborhood occupants, it is impossible that clients will have the capacity to buy a wide assortment of sound nourishments (Bodor, M. Ulmer, Dunaway, A. Farley, Rose (2010)). Markets and general stores are monetary stays in an area-providing nearby occupations and making pedestrian activity for extra organizations (Treuhaft, Sarah, Karpyn, Allison)

The accessibility of numerous empowering sustenance things and create quality are more terrible in bring down wage territories, yet nourishment costs are not higher. Despite the fact that inhabitants of low-pay groups have preferable access to general stores over prior, many still shop in little neighborhood stores without stimulating nourishment choices. Given that cost contrasts between such stores and markets have expanded since 1971, absence of access to supermarkets has turned into a much more critical driver of incongruities in consume less calories quality. (Andreyeva, M. Blumenthal, B. Schwartz, W. Long, D. Brownell (2008)).

\section{Research Methodology}

\subsection{Introduction}

The study will be empirical in nature and the research will follows the quantitative methods. In this research report at first, we will set the goal for this research. At that point we will do broad writing audit on changes in the consumer buying pattern on introduction of one stop shops and it's after effects. After that for finding the responses to target we will arrange questionnaires in light of Likert scale. At that point we are going to gather information from the clients who go for purchasing in large grocery stores or the ones who has experience of purchasing in large grocery stores in past. At long last, we will enter information in SPSS and examine the information according to the variable and according to request of our destinations. 


\subsection{Research Philosophy}

This research will be furthered carried out on the basis of positivism research philosophy as the problem identified will be supported by logical and mathematical proof.

\subsection{Research Strategy}

Data collected here will be based on Survey approach as questionnaires will be filled by the people who use one stop shops for shopping and who has experienced shopping at large stores, either their usage rate is light, medium or heavy, of all age group, family size, both genders and of all income levels.

\subsection{Hypothesis}

\section{Inflation}

HO: There is no relationship between introduction of one stop shops and Inflation.

HA: There is a positive connection between introduction of one stop shops and Inflation.

Increase in Impulse Buying

HO: There is no relationship between introduction of one stop shops and Impulse Buying.

HA: There is a positive connection between introduction of one stop shops and Impulse Buying.

Danger of Health

HO: There is no relationship between introduction of one stop shops and Danger of Health.

HA: There is positive connection between introduction of one stop shops and Danger of Health.

\section{Traffic Jam}

HO: There is no relationship between introduction of one stop shops and Traffic Jams.

HA: There is a positive connection between introduction of one stop shops and Traffic Jams.

Survival of Small stores

HO: There is no relationship between introduction of one stop shops and Survival of Small Stores.

HA: There is a positive connection between introduction of one stop shops and Survival of Small Stores.

Rising prices of neighbor society

HO: There is no relationship between introduction of one stop shops and rising prices of neighbor society.

HA: There is a positive connection between introduction of one stop shops and rising prices of neighbor society

\subsection{Research Design and Data Collection Method}

The investigation we will be directing depends on the proposed speculation as we will be trying whether the theory that we set are legitimate or not. In addition, the sort of examination we will do is correlational investigation i.e. regardless of whether an expansion or abatement in one variable relates to an increment or reduction in the other variable. Here, we will discover in the case of rising pattern of shopping at Supermarkets expands Inflation? Acquainting stores will lead with congested roads because of stopping issues? Substantial markets are diminishing the survival likelihood of little stores? Selling of processed packaged frozen food in one stop shops reducing the nutrient content leading health under threat? Items in basic need thing will prompt motivation purchasing? Whether Opening of large Supermarkets, grocery stores, hypermarkets etc. are increasing the prices of neighbor society? We will accumulate essential information by making respondent fill questionnaire. Secondary Data is going to be collected through Published articles, journals, news, internet, magazines etc.

\subsection{Sampling}

The universe of the examination is customers/clients who go for acquiring essential supply thing. This examination relies upon Convenience Non-Probability Sampling Method. Convenience testing is utilized as a part of picking the respondents as per the settlement or straightforward passage for the specialist. For this Research paper 200 polls will be appropriated among the customers/purchasers/clients of market. The specimen measure (sample size) chosen for this exploration is 200.

\subsection{Data Analysis}

To calculate the findings and to test the hypothesis SPSS will be used.

\subsection{Limitations}

- Some of the proposals are not sponsored by quantitative essential research but rather depend on learning of the market and best practices.

- The nonattendance of time to finish an audit/do a study.

- The nonattendance of sponsoring/financing vital to do an examination/complete an overview.

- Data may not be adequately effective to elucidate complex issues.

- The land impediments set to direct this examination just incorporate one city of Pakistan, limits the 
degree and range of this exploration.

- $\quad$ The test may not be geologically comprehensive.

\section{Chapter 02: Literature Review}

\section{Factors Rising After Introduction of One Stop Shops}

\subsection{Inflation}

As said by (Levell, P., and Skingle, T. 2012) singular families may encounter expansion rates which are altogether different from this normal. One purpose behind this is family units spend their financial plans in various ways thus will feel the effect of given value changes increasingly (or less) than others. Family unit spending designs - thus swelling encounters - could change deliberately crosswise over various gatherings. For example, bring down pay family units have a tendency to spend a greater amount of their financial plan on sustenance, implying that when nourishment costs are rising rapidly, low salary families will encounter higher swelling rates than high wage ones.

As time goes on, swelling is caused by an excess of development in the cash supply. Financial swelling is awful in light of the fact that it clouds the value flags that influence our market framework to work productively. The activity of financial arrangement is to supply recently the perfect measure of cash with the goal that the normal value level stays stable. Over brief periods, in any case, swelling can be impacted by expansive changes in the market for specific products and ventures. Since these episodes of swelling have a tendency to be brief and self-rectifying, the best possible money related arrangement reaction is to disregard them. The issue for the Federal Reserve is to know when swelling is because of over the top financial development (requiring an approach reaction) and when it is because of temporary market variances. To deal with the short-run genuine impacts caused by interruptions to specific markets from the long-run fiscal impacts caused by Federal Reserve approach, financial specialists have created methods to channel the expansion news. Generally, financial experts have avoided nourishment and vitality costs in their sifting procedure, yet we find that by sifting through sustenance costs, we may lose important data about expansion. Another adjustment in the sustenance dispersion framework is that numerous more individuals now purchase their nourishment from vast market chains. These extensive chains have preference over littler claim to fame retailers in that they can stock bigger amounts of numerous more extraordinary sorts of things. Extensive stores buy nourishment specifically from the makers in gigantic amounts, slicing the cost to themselves and their buyers. Individuals are significantly more prone to purchase arranged dinners at the market or to eat at eateries. The costs that purchasers pay for these suppers are to a great extent uses on the work used to plan and serve the nourishment. The cost of these work administrations is less unstable than is the cost of the crude nourishment items (Gavin, W., and Mandal, R. J. 2002).

In this paper (Buzacott, J. A. 1975) it is demonstrated that with expansion the decision of the stock conveying charge utilized as a part of the EOQ recipe relies upon the organization's estimating approach. In the event that costs change autonomously of recharging request timing the stock charge ought to be low and free of the expansion rate. In any case, when no "twofold ticketing" is allowed and the organization utilizes a consistent rate increase the conveying charge is high and relies upon the expansion rate and the increase. Just if the organization is permitted settled money related edge is the established come about for conveying charge legitimate.

According to (Hayes, A.) Expansion is caused by the general augmentation looked for after for stock and ventures, which presents their expenses. This theory can be plot as "an abundance of money seeking after unnecessarily couple of items". Toward the day's end, if ask for is ending up speedier than supply, expenses will increase. This for the most part happens in quickly developing economies.

(Nevo, A., Leibtag, E., Leicester, An., and Griffith, R. 2009) The rule objective in this paper is to document the potential and genuine hold supports that purchasers recognize from various estimations of choice and how these change with buyer economics. Their consideration was on four particular sorts of getting conduct: acquiring marked down; buying in mass; buying non-particular brands; and picking outlets. What sum can and do families save through each of these practices? They utilized information gathered by a showcasing firm on all sustenance buys brought into the home for a vast, broadly illustrative specimen of U.K. family units in 2006. They additionally watched family socioeconomics. Utilizing this information, they could quantify how significantly less customers pay when they buy at a bargain, purchase bigger packs, go to another retailer, or purchase a nonexclusive brand. We think about two extra decisions - to purchase in mass and to purchase marked down - made by buyers and ask how they contrast with different types of substitution that have been stressed in the writing. The outcomes propose that reserve funds from deals and mass purchasing are of a comparable request of size to those because of economy brands and outlet decision. U.S. homes are bigger and customers tend to shop more with autos, so transport and capacity costs are lower. Subsequently, bigger sizes not just have a tendency to be all the more regularly bought in the United States yet additionally offered more by stores. 


\subsection{Impulse Buying}

Indicated in the research of (Yarahmadi and Hasti, 2011), there arise a principle connection between two variables, outside signs and drive purchasing conduct i.e. impulse buying. Considering Sample size of 275 respondents, the information related to these variables was assembled and gained in July 2010 in country Iran. The research aims to identify impact of independent variable outside signs that are window shows, charge cards, limited time exercise items such as money rebates and free items on the dependent variable motivation purchasing conduct of buyers i.e. impulse buying. Data was analyzed through two software programs SPSS and LISREAL. The result from running the t-test interpreted that attire motivation purchasing and limited time approaches are having more use alongside the example. The researcher proposed for the installation of ATM machine for the customers and provides appreciative blessings to them for scrutinizing for drive purchasing conduct.

The quantitative theory was examined by (Raheem, Vishnu, and Rizwan, 2013) related to impulse purchase behavior of different respondents in the city Larkana. The gathered information related to buyer's sentiments identified with their theme concluded that variables like Free items, salary level, value rebates, brilliant environment, quiet condition of store, window show, better situation and introduction of items are assumed as an indispensable part to make the customers rasher.

As analyzed by (Saraswat and Prakash, 2013) in their research that youthful age is the main target audience in investigation on drive purchasing. Many researchers have conducted research on impulse buying and its driving factors in retail locations to build it in an extensive way. The conclusion they arrived on portray the fact that many retailers work on pleasurable store condition, limited time plans, eye getting introduction of different items to draw in the clients towards drive purchasing.

(Park \& Choi, 2013) This quantitative researched is based on the exploratory investigation on the impact of unplanned purchased drive from motivational factor across different cultures. Information gathered in this researched was gained through inside and out concentration interviews from American and Korean clients to show the social contrasts. The outcome finds out that there lies a huge difference between expected and ordinary purchase. Different Customers additionally witness that clients likewise observed motivation purchasing in a negative light. Due to different analyzed and identified variables more research should be conducted to closely analyze the store environment for more additional factors, for gaining better understanding of motivation purchasing and shopping buy.

As stated by (Hadjali, Salimi, Nazari, and Ardestani, 2012) in their research report, impulse purchase has a great impact on customer buying behavior. The research targeted the purpose of exploring some huge components influencing on motivation purchasing conduct in mix with array. A little data related to motivational purchasing was available in eastern and value-based social orders. Through running different numeric finding in the SPSS program, it was found out that Limited time devices, shopping condition, sexual orientation, peevishness have real effect on drive purchasing conduct while obtaining garments.

They (Mathai, Thomas, \& Haridas, 2014) in their research tried to find out a connection between motivation purchasing and identity characteristics of clients. The respondents were the residents of Kochin city. They analyzed that due to accessibility of charge cards facility, in sore jolts, influence of offers staff and client's identity qualities, greater part of the clients is arranging their purchasing inside the store. The data was gathered through Big Five Personality test and was run in SPSS for interpreting the outcomes through ANOVA. The outcome demonstrated that identity highlights have mind blowing sway on motivation purchasing conduct, as each and every $\mathrm{F}$ esteems are critical aside from the items at rebates. The different correlations broke down that Extrovert identities are mostly identified as being making real drive purchasing than others.

In this research, the analyst (Zhou, H., \& Gu, Z, 2015) inquire about the major connection between various value introduction, purchaser motivation purchasing aim and customer feeling of expected lament. The variables selected for research were motivation purchasing, value introduction and foreseen lament. An aggregate of 340 college understudies from Jinan University took an interest in the analysis. They were haphazardly relegated to a situation condition. In this trial, we get back 319 accessible polls in light of the measure of cash/in light of the rate off, and the successful rate is $93.82 \%$. The quantity of men and ladies in the specimen are generously equivalent. Through SPSS we broke down the unwavering quality and legitimacy of the survey. Research at last accomplished the ending that esteem discounts in light of the measure of money could energize greater capacity to buy, once customers got restricted time rub, they might be hesitant to miss the shot of acquiring more affordable things, that is the point at which the item is in a high value level, the value advancement shape in view of the measure of cash assumes a huge part; when the item is in a low value level, two markdown frames exhibit no huge contrast.

This quantitative research (P. R. M. Vishnu, A. A. R., and Raheem, A. R. 2013) aims to discover every one of the elements those impact rash purchasing conduct and to break down contrast in male and female incautious purchasing conduct. For this 5 variables effect was examined i.e. the impact of special methodologies, store condition, out of store display, income level and ATM cards on drive buying conduct. The analyst used Non- 
Likelihood Stratified examining by utilizing persuade strategy to gather the information from male and female by distributing 384 questionnaires dispersed physically among the respondents and nationals of Larkana. Substantial and usable information was run on SPSS 20 version software for generating outcome on Reliability of scale, Frequency, Cross tables, Correlation and Regression. The outcomes translated that the pay level, window shows and visual marketing has exceedingly and fundamentally effect on purchaser's drive buying for FMCG's (items) in Larkana. And all-around enhanced, with charming and quiet store condition besides bright surroundings propelling the shoppers to buy accidentally as well as fabricate fervor inside the buyer's brains.

As per these researchers (Ardestani, M. S. Hadjali, H. R., Salimi, M., Nazari, M., and 2012) in their theory suggest that the expanding development in utilization and plausibility of credit buys far and wide through charge cards has given a superb chance to purchase unexpectedly (incautiously). The examination was carried out to investigate some fundamental elements influencing on drive purchasing conduct in conjunction with apparel advertise. The time of study was in summer that situated at celebrated shopping centers in Tehran. The respondent's gatherings were chosen among customers who were going to dress markets. The poll of this examination distributed among respondents was composed by utilizing existing surveys. In spite of reacting test comprised of 120 shoppers, at last number of respondents who did the examiner accurately was made out of 110 individuals. For deciding the legitimacy of the survey Cronbach's Alpha was utilized. Results from SPSS programming demonstrates the level of confidence, fractiousness (impulsivity), Shopping condition, special apparatuses and sexual orientation have a major effect on motivation purchasing conduct particularly to purchase fabric.

The paper written by (Saif, M. I. Tirmizi, M. A., Rehman, K. U., \& 2009) examines the connection between free factors which are shopping way of life of customers, mold association of buyers, pre-choice stage and postchoice phase of shopper buy conduct with drive purchasing conduct. This examination endeavors to investigate the affiliation exists between the factors required from the respondents of Rawalpindi and Islamabad. Using convenient sample and non-probability sampling method reactions of 165 respondents from higher salary amass was gathered. The real discoveries of the investigation showed a general powerless relationship of the arrangement of autonomous factors with the needy variable at the same time, consequences of this paper demonstrated no relationship of motivation purchasing in higher pay gathering of youngsters having predominant drive purchasing inclinations. This examination definite new affirmations in the field of drive buying behavior of purchasers identifying with the close-by business sectors of the twin urban groups of Pakistan. The start to finish examination found that pre-decision period of purchaser purchase lead is the principle variable that came to fruition into strong association with the inspiration acquiring conduct. It's real that youths more consistently get pulled in to things appeared on store resigns and has more vital penchant of drive acquiring conduct.

This quantitative investigation proposed by (Lodhi, M. J. S.) went for featuring the effect of outside and inner variables that impact buyer motivation purchasing conduct at one stop shops in Karachi. Two factors were chosen i.e. Subordinate variable and Independent factors. Subordinate variable include "Purchaser drive purchasing conduct" and Independent factors in particular outer elements (Visual marketing, Shopping condition and Promotional exercises), inner elements (Gender, Credit card and hedonistic inspiration). Test measure was 265. SPSS software was utilized for information investigation. The result of the present investigation checks that there is a urgent connection between visual marketing, limited time exercises, shopping condition, sex, charge card and hedonistic inspiration with buyer drive purchasing conduct. Customers will probably purchase incautiously when they see the bright environment and quiet condition spurring the shoppers to purchase automatically as well as construct fervor inside the buyer's psyches. Visual marketing and hedonistic inspiration and shopping condition have a vital pretend for buyer's drive purchasing. The accessibility of charge cards and special offers likewise some way or other impact shoppers for drive purchasing.

(Nagadeepa, C., Selvi, J. T., and Pushpa, A. 2015) in their research indicated that one of the key components of special blend i.e. Sales advancement is being utilized generally by the advertisers to contend and maintain the upper hand and thus increment the deals by animating the buyers' buy choice. This research work has tried to recognize the different deals advancement strategies and the request by which they impact the shoppers' basic leadership towards clothes. Deals advancement strategies such as cut partial refund, price offers, discount vouchers, rewards Programs, Reduced price marked on package and Contests are considered in this examination. A self-managed poll is arranged and aggregate of 110 respondents are met with it at Bangalore. Utilizing the SPSS apparatus, the gathered information is dissected and it is discovered that partial refund, cut price offers and rewards programs have huge connections towards the motivation purchasing conduct.

(Crawford, D. A., Cameron, A. J., McNaughton, S. A., Worsley, A., and Thornton, L. E., 2012) in their research proposed a theory that stores assume a noteworthy part in affecting the sustenance acquiring practices of generally family units. They further said that Nibble nourishment exposures inside these stores may add to more elevated amounts of utilization and at last to expanding levels of weight, especially inside financially distraught neighborhoods. To prof their saying this research meant to analyze the accessibility of nibble 
nourishment shows at checkouts, end-of-passageway presentations and island shows in real grocery store chains at all and most financially burdened neighborhoods of Melbourne. An Inside store reviews of 35 Melbourne one stop shop was done. Grocery stores were tested from the minimum and most financially impeded rural areas inside thirty $\mathrm{km}$ of the Melbourne. The results found out that Because of the high accessibility of nibble nourishment shows such as crisps, chocolate, sweet shop, and soda pops (eating regimen and standard) at the checkouts, in end-of-path shows and in island receptacle shows is practically unavoidable in Melbourne general stores, paying little respect to levels of neighborhood financial burden. Consequences of this examination could advance familiarity with the noticeable quality of unfortunate sustenance things in chain-mark stores outlets.

As said by (Bhakat, Muruganantham, \& Shankar, 2013) in their research that better analyzing the drive purchase i.e. impulse buying conduct of shoppers has been an inducement for scientists because of its having many different aspects or features identity. The primary target of this examination was to give far reaching portrayal of motivation purchasing conduct of shoppers by social event distinctive customer investigate work by perceiving different factors in different nations and economies. Because of present day strengthen in culture and retailing, a colossal change has seen in income level, standard of living and credit. In the country like India, the retail parts provide a larger range to wind up noticeably rash for customers on the web and disconnected both for different items.

\subsection{Danger of Health}

To target of this exploration (Ball, K., Roberts, R., Campbell, K., Andrianopoulos, N., Timperio, A., and Crawford, D. 2008) was to look at relationship between accessibility of various sorts of nourishment outlets and kids' foods grown from the ground consumption. 340 Parents of 5- 6 and 461 Parents of 10- 12-year-old Australian kids announced how every now and again their tyke ate 14 products of the soil vegetables. A geographic data framework was utilized to decide the accessibility of the accompanying sorts of sustenance outlets close home: greengrocers; markets; accommodation markets; inexpensive food outlets; eateries, bistros and pic-up outlets. Strategic relapse investigations analyzed the probability of expending natural product and vegetables times/day, as per access to nourishment outlets. The outcomes uncovered that accessibility of inexpensive food stores and comfort stores near and dear may negatively affect kids' leafy foods consumption. The positive relationship between separation to the nearest general store and the probability of devouring vegetables no less than three times/week is as opposed to investigations of grown-ups and requires encourage examination.

This exploration (Siega-Riz, A. M., Kaufman, J. S., Laraia, B. A., and Jones, S. J. 2004) explores the relationship between separation to the nearest grocery store and a composite measure of eating regimen, the eating regimen quality file for pregnancy (DQI-P) was built. Sustenance recurrence polls were utilized to develop DQI-P which incorporates: servings of grains, vegetables, organic products, fol-ate, iron and calcium admission, level of calories from fat, and dinner design score. Road address of home, markets, basic supply and comfort stores were geo-coded. Members with finish nourishment recurrence and address information were incorporated $(\mathrm{n}=918)$. These discoveries recommend that vicinity of sustenance retail outlets impacts the eating regimen nature of pregnant ladies. A lady's nourishment condition, as measured by separation to markets, supermarkets, and accommodation stores, specifically affected eating routine quality amid pregnancy. Living more prominent than 4 miles from the nearest market is most firmly connected with terrible eating routine quality, even in the wake of check-in-balance for persons monetary traits and the openness of essential supply and convenience markets.

This article (Cheadle, A., Wagner, E., Diehr, P., Koepsell, T., Psaty, B. M., Kristal, A., and Curry, S., 1991) inspects the relationship at the group level between singular dietary practice and the supermarket condition. Singular dietary practice was measured in 12 groups utilizing a phone study to get self-revealed abstain from food $(n=34)$. A convention was created to quantify two parts of the market condition in these same 12 groups: the comparitive accessibility between invigorating (low-fat and high-fiber) items and the measure of wellbeing training data gave. The outcomes exhibited propose that it might be conceivable to take after changes in dietary practices in a group by following improvements in supermarkets. There is additionally provisional help for the theory that there are connects between the group condition and individual states of mind and conduct.

(Morland, K., Wing, S., and Roux, A. V. D. 2006) The reason for this examination was to analyze whether qualities of the nearby sustenance condition (Supermarkets and other nourishment stores) are related with the commonness of cardiovascular ailment hazard factors. Names and addresses of sustenance stores situated in Mississippi, North Carolina, Maryland, and Minnesota were gotten from divisions of horticulture. Multilevel demonstrating was utilized to compute commonness proportions of the relationship between the nearness of particular sorts of sustenance stores and cardiovascular illness hazard factors. Results from this examination recommend that attributes of neighborhood sustenance conditions may assume a part in the counteractive action of overweight and weight. The accessibility of supermarkets and accommodation stores is related with an expanded pervasiveness of overweight and weight among inhabitants. 
This exploration (Devlieghere, F., Berkvens, D., Vermeulen, An., Uyttendaele, M., and Van Boxstael, S., 2014) characterized the comprehension and mentality in regards to the time-frame of realistic usability names and dates on prestuffed nourishment items by Belgian purchasers. In light of an on-line study utilizing polls, data on Belgian purchasers $(\mathrm{n}=907)$ with respect to their comprehension and state of mind towards time-frame of realistic usability names and dates was gathered. It was demonstrated that the time span of usability date on prestuffed nourishment items speaks to an essential grapple point for the Belgian shopper in the intricate procedure of choosing the adequacy of expending sustenance items. Buyers decipher the time span of usability information and name in an adaptable or stricter route contingent upon the sort of sustenance.

\subsection{Traffic Jams}

As reported in (Pakistan Observer, October 21, 2017) the opening of a store on primary Rashid Minhas Road in Gulshan-e-Iqbal, Karachi, has ended up being a wellspring of disturbance — not the only one for the territory occupants, but rather additionally for drivers who handle the significant avenue. Colossal congested roads were seen in the region after the outlet's opening. Workers were left stranded in the gridlock for quite a long time, leaving activity police defenseless in clearing growl ups. The general store was somewhat a bane for workers as the adventure of a couple of minutes took a few hours which tried their understanding under the burning sun. The nonattendance of legitimate and adequate stopping offices at the general store is the primary purpose for the turmoil. It might be specified that another well-known store is additionally situated crosswise over inverse segment of the street. Boss Minister Sindh Qaim Ali Shah has paid heed to the episode and requested an investigation into the illicit stopping outside the store.

(Van der Waerden, P., Timmermans, H. and Borgers, An. 1998) Although land specialists, advertisers and urban planners underscore the significance of the connection between the area of general stores and different stores and the areas of parking garages, better exact research must be directed to test this relationship, particularly in a prior and then afterward consider. The motivation behind the investigation was to fill this hole in our observational learning. A various leveled decision display was assessed to test the theory that, customers selection of markets is impacted by store qualities and the separation between the general store and the parking garage, that the likelihood of picking a parking area increments with an expanding size of the parking area, a positive area of the parking area opposite the root of the buyer, and the accessibility of grocery store trolleys, that a consecutive basic leadership process speaks to the decision procedure sensibly well, and that this relationship is moderately consistent after some time. The information for the investigations was gathered in one of the significant strip malls (City Center Veldhoven) in the Eindhoven Metropolitan territory through meeting. The consequences of our investigation demonstrate that these theories are in part bolstered. The buyer's selection of markets is affected by store attributes and furthermore by parking garage qualities. Most impacts are of course, with the exception of the one for the quantity of parking spots. The likelihood of picking a parking garage diminishes with an expanding size, recommending that clients need to maintain a strategic distance from long strolling separations. The estimation comes about demonstrate that a consecutive basic leadership process speaks to the general store and parking area decision process well.

(Axhausen, K. W., and Polak, J. W. 1991) expressed that over late years, stopping approach has turned into a key component of transport arrangement in numerous nations. Stopping strategy measures can influence a wide range of measurements of travel conduct however are probably going to be most critical as far as voyagers' decision of stopping sort and area. This measurement of travel decision has, to date, got nearly little consideration, yet is of essential significance in the event that we are to legitimately comprehend and anticipate the impacts of stopping approach measures. This paper presents two investigations tending to this issue completed in the United Kingdom and Germany. The two examinations utilized an expressed inclination approach with a specific end goal to gather dis-aggregate information on voyager's reactions to changes in stopping qualities and utilized this information to fabricate basic legit models of stopping sort decision. The outcomes got firmly demonstrate the need to independently distinguish the expenses related with various segments of the stopping action (e.g., general in-vehicle time, stopping seek time, departure time) and furthermore point to the presence of critical contrasts in the relative valuation of these segments crosswise over various adventure purposes.

As said by (Hamze, Abrar, June 2, 2016) the super stores have turned into another danger for the general population of Karachi who are as of now confronting extreme activity perils, and this circumstance would deteriorate in the period of Ramadan that is just seven days ahead. It has been learnt that Chase Departmental Store and Imtiaz Super Market are the principle reason of illicit stopping on lanes prompting substantial car influxes on busiest streets of the city, making the workers' life troublesome. The SBCA is additionally among the in charge of such car influxes in the city as the expert is offering authorizations to these super stores without guaranteeing that whether they are putting forth parking spots or not.

(Domingo, Katrina. September 22, 2017) Traffic-fatigued buyers might move far from mammoth staple goods, as demonstrated by developing conveyances to littler stores in Manila, Capital of the Philippines. The 
area basic supplies are additionally a route for retail organizations to contend with accommodation stores, bigger stores, be that as it may, in any case bid to the individuals who need to purchase in mass.

In a general public where families want to do shopping from grocery stores and shopping centers, clients hope to discover all products and ventures inside one place. Driving starting with one grocery store then onto the next has dependably been a bother, the present practice where a wide range of activity mix on a similar carriageway does not permit simple development while shopping. Given that many strip malls don't have sufficient parking spot, drivers are compelled to stop along fundamental street areas. This prevents powerful street use and causes blockage. It likewise adds to rendering areas of street paths unusable in light of the fact that vehicles line up the whole path. Meanwhile, the nonattendance of one-stop focuses, should compel us to consider making open parking areas. On the off chance that open stopping was given, current movement volume would be dealt with productively (Mone, J., Simon, July, 01, 2014).

This paper (Abbas, K. A. 2004) builds up a bland system of the procedure engaged with leading movement affect appraisal (TIA) for uber edifices, applies it to a true one of a kind venture and infers lessons of utilization in comparable circumstances. The procedure includes reviews and examination of present activity and person on foot course frameworks, and stopping and travel conditions, to set up current levels of administrations, movement issues and issues. The fundamental objective of movement affect evaluation is to recognize, inspect and survey activity initiated impacts from arranged new advancements and land utilize changes. The relevance of the TIA procedure was researched as for San Stefano stupendous court in Alexandria, Egypt, one of the greatest improvement extends in Egypt and the Middle East, including different changes to the encompassing area utilize design. The investigation has demonstrated that it is normal that movement on the encompassing system of streets would reach, and even surpass, the limit of all convergences and street joins. This would prompt an entire street blockage of the site at top periods. The effect of the limit shortage is basic, not just on the potential utilize and commerciality of the complex, yet in addition on the encompassing street organize, which should bear the weight of retaining neglected request. Methods for alleviating unfavorable impacts were investigated and surveyed. The proposed TIA process was connected to San Stefano fantastic square, Alexandria, Egypt.

As said in (Matin, F., Herani, G. M., and Warraich, U. A. 2012) investigate due to rapidly alter in establishment of Karachi city and creating people raise the enthusiasm for more workplaces, space and vehicles. It transformed into a basic test for city to manage the flood of development as indicated by routine and plan the courses through which issues can change and point of confinement the future issues. In this subjective research examine exploratory approach has been utilized and essential information was gathered through polls; field overview, individual perceptions and meetings. Optional information was gotten from different government workplaces and concerned offices. Other than counseling distinctive diaries, examine reports, web and a few daily papers were likewise used to remove the required data. Specialist's perception and experience fill in as an impetus to investigate the verifiable finding in a suitable way. This investigation finished up the key issues for car influxes are development of new building, strip malls, Less stopping offices, Impact Road Design, Encroachment on street and Footpad, Movement Signals and roundabouts, Inefficiency of development police, more vehicles on road, Violation of action oversees by drivers and Political and other fomentation. It is prescribed that all administration offices identified with the vehicle division must be under one window for their better coordination and administration. General Awareness must be created in people in general. To decrease the speediest ever activity development, the utilization of private autos ought to be disheartened through the presentation of better than average open transport, including round rail and travel transport in the city.

(Sivanand, Kommina, January, 26) said I was struck in movement at PG street, Hyderabad. 10 mins passed, still there was no development. I leave auto and found that there are no police. It is a four-way intersection. I endeavored to discover the reason for the automobile overload. At that intersection there is market. This involved the stopping zone and set a tent to show items. This constrained people in general to stop out and about which is impeding one-way movement. There is a Wagon $\mathrm{R}$ auto stopped out and about. I went to market yelled the auto number and found the proprietor. I cautioned the store chief. I cleared one-way activity. I thought I was practically done; interim an auto from wrong way deterred the movement. I sent him back. At last the activity was cleared. The explanations behind congested driving conditions are many shopping centers and business structures possess the basement which is implied for stopping for extra rental wage, this power open to stop on streets. While in congested driving conditions, many originate from inverse side with no presence of mind. They believe that individuals holding up are generally tricks. This makes the jams considerably greater. Cars are one of the fundamental explanations behind the jams. You can never anticipate next turn of a tornado and an auto.

\subsection{Survival of Small Stores}

This quantitative research which incorporates the Positivist worldview (Jaliawala, M. M. 2014) examined that the approach of marked basic supply affixes has constrained clients to change from customary supermarkets to marked basic need chains or month to month basic need buy. The point of this investigation is to investigate the 
clients' level of changing over from conventional supermarkets to marked basic supply chains and furthermore to discover the determinants of changing over from customary markets to marked basic need chains in Karachi. This marvel has been as of late seen in Pakistan. The deductive approach is utilized and convenience sampling technique is used. Closed-ended questionnaire WERE utilized as research instrument and SPSS factual programming is utilized for information examination. Aggregate of 105 legitimate polls were gotten; 35 from each store. To find out level of exchanging over the results showed that $90 \%$ of the respondents have been purchasing for 4 months or more from marked basic need chains. The exploration examine uncovers that the 3 autonomous factors that are Proximity, Environment and Engagement are associated with channel exchanging with closeness having a low relationship.

In this research (Batislam, E., \& Filiztekin, A. 2011) explored the degree and factors of progress between retail diverts amid retail modernization in Turkey. Family units are examined amid six years, utilizing family unit board information covering basic need buys from grocery store, neighborhood advertise and conventional directs in Turkey. Discoveries of the examination were customary channel still keeps the most elevated steadfast client base in Turkey. Family units faithful to conventional channel exchange either a little measure of their buys to current channels or make present day channels their real channel at times. Regardless, there is a progress period experienced in Turkish basic need retail advertise. A multi-channel use conduct or higher selection to present day channel may me the aftereffect of this progress.

In this research the analyst (Borraz, F., Zipitría, L., Ferrés, D., \& Dubra, J. 2014) separate the effect of market section on the exit of little kiryana stores in the support retailing territory in Montevideo in the region of 1998 and 2007. We use quick and dirty land information to recognize the association between market area and the exit of adjoining little stores. The poor variable is a spurious variable that shows whether a little store was open or not in a given year. They focus on recognizing the effect of store area on the probability of survival of little sustenance retailers. Passage of markets utilizing little to medium-estimate designs makes an aggressive risk for the current little stores, diminishing their likelihood of survival. The outcome is vigorous to a few model details and differing meanings of what constitutes a market. The effect of store passage is unequivocal for basic supplies, bread shops, crisp pasta shops, and butcher shops.

As analyzed by these analyst (Yadav, R. K., Verma, M., \& Singh, S. 2016) that in India development and change of retail showcase on one side making a superior shopping knowledge and opposite side it is making a great deal of weight on sloppy retailers. The principal goal of this examination is to comprehend the view of little kiryana shops in connection to the effect they can have and the second is discover the impact on their work with the expanding number of corporate retail chain stores as sorted out retail locations in comparing basic need section. The investigation was done in the Indore area and reactions were gathered from little shops and markets. Multivariate factual methods were utilized to dissect the information gathered with the assistance of an organized survey. The consequence of the investigation demonstrates that little shops proprietor saw that their benefit is adversely influenced, their operational cost is expanded to meet the upper administration quality desire of the client however the outcome don't indicate huge negative effect on their work because of development of corporate retail locations. The ramification of the examination is that small shops need to actualize new techniques to confront the opposition from retail monsters and satisfy the client desires to stay productive over the long haul.

As expressed in their research (Batislam, E. P., \& Filiztekin, A.) that due to retail modernization increase in channel decent variety which proceeds in creating nations. A Rivalry turns out to be much more troublesome when there are channel choices grew locally, offering benefits like both current and traditional channels all the while. This examination breaks down the degree of retail modernization and direct expansion in sustenance retail showcase in Turkey between the years 2000 and 2005. It concentrates on inspecting the advanced divert dissemination in various financial levels and item classifications to characterize the main considerations impacting the rate of dispersion. The information utilized as a part of this examination are gotten from the database that are HTP Research and Consultancy Co. has created with a specific end goal to plan different business gives an account of the retailing and quick moving buyer products division in Turkey. In dissecting the advanced direct dispersion in various financial levels, it is watched that upper financial gatherings embraced more to present day channels and exchanged lion's share of their spending from conventional to current channel as image of their standard while the moderate selection pace in bring down financial gatherings ought to be for the most part because of the trouble of transportation, the absence of funds essential for mass purchase and the absence of the space to store expansive amounts of shopping.

(Lodish, L. M., Montgomery, A. L., and Fox, E. J. 2004) show an observational investigation of family unit shopping and bundled products spending crosswise over retail arranges - markets, mass merchandisers, and medication stores. Their investigation considers rivalry between these organizations and investigates how retailer variety, evaluating and limited time arrangements, and additionally family unit socioeconomics, influence shopping conduct and consumptions in these distinctive configurations. This examination is made conceivable by another board dataset gathered by Information Resources Inc. (IRI) which catches shopper bundled products 
buys made at elective retail outlets. SPSS programming utilized for information investigation. We appraise a progressive multivariate to bit show which catches customer choices about "where to shop" and "the amount to purchase." We find that shopping and spending shift considerably more crosswise over than inside configurations, and that the retailer's showcasing blend clarifies more variety in shopping conduct than travel time. Of the advertising blend factors considered, we find that uses react more to fluctuating levels of variety (specifically markets) and advancement than cost. This is amazing in light of the basic need industry's endeavors to lessen retail combinations. Value affectability is most obvious at merchants. Customers at sedate stores are more delicate to travel time than different organizations, maybe because of the accommodation introduction of medication stores. We additionally find that family units which shop more at mass merchandisers likewise shop more in every other configuration, recommending that visits to mass merchandisers don't substitute for excursions to the supermarket.

(Ozcan, G. B. 2000) overview was intended to research the survival systems of little and medium retailers in Ankara, the second biggest city of Turkey. The exploration distinguishes new retail frames and their effect on retail business in various social and financial settings. The investigation focused on formal enlisted organizations. An organized poll was regulated; the specimen estimate is balanced for little retailers in each city locale per retail outlet, an arrangement of top to bottom meetings was additionally directed with business pioneers and key witnesses. The hands-on work recognized thirty-eight stores claimed by substantial multinational and national organizations, fifty-five stores of huge local retailers, and twenty stores of medium-sized nearby retailers. Our review uncovered that in spite of the expanding nearness and energy of extensive retailers there is still space for little retailers in an exceedingly divided and blocked off land setting of the city. While little retailers keep on suffering from intense rivalry, the piece of the pie of substantial present-day retail outlets is relentlessly expanding. In upper-and center salary regions, the customary significance of neighborhood stores is vanishing and little retailers are losing faithful clients. The retail spaces made by the controlled conditions of shopping centers and hypermarkets have made shopping a relaxation action and enabled Turkish ladies to be more portable.

(Krider, R. E., Ramaswami, S., and Goldman, A. 2002) look into show a structure to investigate constraints to piece of the pie development of retail organizes in view of dispersion crosswise over shopper fragments and by item class. They at that point proposed an estimation approach, in view of shopper reviews, that measures the effect of these procedures on grocery store piece of the overall industry. Sustenance retail modernization is then inspected in Hong Kong by this approach for two focuses in time. In a 1995 demonstrative investigation, they locate that geographic and monetary fragment dissemination of stores is finished, however that item class subordinate dispersion (particularly perishables) isn't. The last mentioned, in this manner, turns into the real limitation on general store share pick up. In 1999, a moment ponder measures the effect of the presentation of superstores, a substantial current arrangement, on the perishable confinement to current organization share development. Purchasers saw superstore perishables to be better than stores', however these perspectives had little effect on the capacity of present day configuration to wrest extra offer from conventional markets.

As said by (Farhangmehr, M., Marques, S., and Silva, J. 2000) since its appearance in the mid-1980s, the one stop shop is an image of the standard of Portugal. It has drastically changed the retailing structure in this nation as well as Portuguese purchasing conduct. To better comprehend these progressions, individual meetings were led with 500 Braga buyers. Moreover, a sent overview was regulated in a similar market to 204 conventional retailers. The outcomes demonstrate that, for buyers, the hypermarket is the favored sort of retail location for as often as possible obtained bundled merchandise, because of its low costs and helpful one-quit shopping. The impression of conventional retailers is that the hypermarkets influenced them adversely. The near examination recommends that, despite the fact that purchasers don't have a negative sentiment about customary retail, they don't have the same positive conclusion that conventional retailers have about themselves.

This article (Goswami, P., and Mishra, M. S. 2009) tries to comprehend whether Indian customers are probably going to move from customary small stores to extensive composed retailers while looking for basic needs. Two theories were proposed i.e. client support varies for various market qualities and client impression of supermarket characteristics contrast for small stores and sorted out retailers. The examination was completed crosswise over four Indian urban areas two noteworthy and two littler urban areas with around 100 respondents from every city. Stratified deliberate examining outline with an example size of 409 was utilized for the examination. Multivariate factual procedures were utilized to investigate the information gathered with the assistance of an organized poll. Customer support to business sectors was seen to be distinctly related to territory, obliging, dependable businessmen, home shopping, neatness, offers, and quality and unfavorably related to movement comfort. Little stores do well on zone however inadequately on tidiness, offers, quality, and steady dependable businessmen. The inverse is legitimate for formed retailers.

As said in this research (Reardon, T., \& Berdegué, J. A. 2002) General stores are quickly assuming control sustenance retailing in Latin America, as it has moved a long way past their unique specialties. Stores and substantial processors are as of now, or quick turning into, the principle retail purchasers in the supply chains of 
handled sustenance's. The stores' and substantial processors' obtainment rehearses - quality and security norms, pressing and bundling, cost, volumes, consistency, installment hones - bigly affect, and are an essential test for, ranchers and supply chains in the locale, the general stores are likewise a major open door; they are both an engine for widening and extending the shopper advertise, and the 'toll corner' while in transit to pitching to the developing markets, the urban territories and the white collar classes. It is exceptionally likely that general stores are in the area as long as possible, since they emerge from, and react to, essential basic change and improvement of the locale's economies. To get ready agriculturists to exploit those open doors and address those difficulties requires extraordinary and quick consideration and a re-outline of improvement technique for the little homestead and little firm segment.

\subsection{Rising Neighborhood Property Prices}

(Van Dalen, G. C., and Urban, S. 2016) look into states that desirable feature or conveniences of a building or place are merchandise or administrations that give some sort of solace to individuals. Generally, they create benefit for the third-party. Cases of such pleasantries are business, great open transport and green space. Disamenities are the inverse: they deliver cost suffered by third party and the vast majority tends to detest them. Commotion, contamination and wrongdoing are cases of such unpleasant things. Vicinity of shops can have a vague impact: from one perspective, adjacent shops give comfort as far as short travel time, yet they additionally deliver clamor and clamor. How is this reflected in house cost? This proposal concentrates on the impact of grocery store vicinity on house costs in Rotterdam in 2012. Two methodologies on nearness are recognized: separation to the closest grocery store and the measure of markets in a specific range. The 10 biggest general store chains in Rotterdam will be broke down. The emphasis is on whether there are contrasts between these grocery store chains and where there are collaboration impacts between house-level and neighborhood-level attributes from one viewpoint and market vicinity then again. This examination uncovers that there are without a doubt contrasts between the grocery store chains. Nearness of Dirk and Plus grocery stores has a tendency to have negative effect on house costs, though closeness of a Spar has a constructive outcome. Cooperation factors demonstrate that these impacts are more grounded in the north than in the south of Rotterdam.

(Addae-Dapaah, K., and Lan, Y. S. 2010, January) The paper explores the connection between strip malls (all in all) and the cost of private properties and additionally the relative advantage, as far as closeness factor impact, of an advanced shopping center and a traditional shop. It is found, through hedonistic examination of 8600 exchanges from 19 open lodging bequests, that closeness to malls by and large charges a premium. Despite the cost suffered by third party due to opening of malls, private properties inside 100-meter range of strip malls charge a higher price than those more distant away in spite of the fact that the value separate relationship isn't vary in such a way while the nearness factor fluctuates from lodging domain to lodging bequest. Moreover, the aftereffects of the investigation demonstrate that private properties close to a town focus with a shopping center charge huge price than those almost a town focus without a shopping center. These discoveries will hold any importance with financial specialists out in the open lodging and approach producers.

This paper as written by (Des Rosiers, F., Beaudoin, M., Thériault, M., and Lagana, A., 1996) examines the impact of both closeness and size of strip malls on encompassing private property estimations, utilizing hedonistic demonstrating. The information bank comprises of a subset of somewhere in the range of four thousand single-confined, proprietor involved lodging units executed everywhere throughout the QUC domain between January nineteen nighty and December nineteen ninety-one. A few useful structures are tried and up to sixty descriptors are utilized. All things considered, every practical frame tried yield acceptable outcomes albeit best general exhibitions are gotten utilizing either a log-straight relationship or the opposite model, with or without a quadratic capacity on separate. Put something aside for the straight and semi-log shapes with squared separation, no extreme col-linearity issues are identified. While the positive effect of mall measure on private esteems is unmistakably illustrated, this investigation presents enough observational proof to help the nonmonotonic of the value remove relationship. The issue is additionally examined by applying a summed-up gamma capacity to the specimen. Results show that the gamma work proficiently catches family units' private inclinations and is effective at demonstrating their area decisions as for strip mall produced consequence. At long last, advertise division by mall estimate plainly shows that each size classification orders a particular gamma work. Ideal separations are individually settled at $0.215,0.310$ and $0.532 \mathrm{~km}$ for neighborhood, group and local strip mall's separately. This examination recommends that, while the gamma capacity can be exceptionally helpful to get a handle on families' area conduct as for shopping-penny recovered consequence, it could likewise be connected to numerous different circumstances including non-monotonic, specifically the nearness to primary schools, parks, greens, modern plants, and so forth. Past hypothetical contemplation's, handy uses for such examinations are likewise very self-evident. Both private designers and family units can receive generous rewards from a superior comprehension of area streamlining ideas. As appeared by discoveries, these could enhance the expert esteem's model prescient precision while likewise filling in as hazard limiting apparatuses for institutional banks. In that regard, additionally inquire about is expected to take a gander at the effect of urban 
consequences on house costs.

This research paper (Matthews, J. W. 2006) takes a gander at the impact of vicinity to business improvement on lodging costs specifically. The examination incorporates controls for kind of non-private improvement and utilization's a creative new strategy to consolidate investigation of neighborhood format as a particular autonomous variable. Consolidation of neighborhood design is a one of a kind commitment of this paper. Reactions were accumulated through polls, state of mind reviews and hedonistic value demonstrating a utilization of numerous relapse systems. There are two essential invalid theories tried: Proximity of business improvement has no impact on costs of proximate private properties, Proximity of business advancement has no impact on costs of proximate private properties paying little heed to the design of the area setting. Both invalid speculations are rejected.

The goal of this exploration (Fossen, V. W. 2017) portrayed in this paper is to decide the impact the presentation of a general store inside a predefined vicinity to an area has on the private property estimations inside that area. The fundamental objective is to decide whether and what premiums grocery stores are adding to homes and how this progression when the separation between the home and the markets changes. The information utilized as a part of this investigation originated from two primary sources. The reliant variable, private property estimations, was acquired from an open database gave by the online land stage, Zillow. The autonomous/logical factors, or the elements that were accepted to affect private property estimations, were acquired from ReferenceUSA. Both far reaching datasets took into consideration a relapse to be kept running to decide the impact that stores have on private property estimations. The aftereffects of this exploration demonstrate that the presentation of a general store in closeness to an area increases private property estimations all things considered. It was watched that inside the one-mile range of an area the presentation of a general store will increment private property estimations by around $\$ 8,000$, inside three miles of an area the presentation of a market will build property estimations by around $\$ 6,000$ and inside five miles of an area this cost increment is seen at a level of around $\$ 4,000$. This distinction in premium backings the instinct that a grocery store opening more like an area would greatly affect the property estimations on the grounds that the shorter separation makes it more helpful.

This paper (Preston, J., Pagliara, F., and Kim, J. H. 2005) has given a broad investigation of the degree to which transport and neighborhood conveniences effect on the choice procedure prompting private area decision, utilizing Oxford-shire, UK, as a contextual investigation. It likewise features the exchange off between access, space and different traits in private area decision. Specific accentuation is put on evaluating the effect of transport and area installed civilities. A settled legit show is connected to evaluate the backhanded arbitrary utility elements of the aim to move and private area decision in light of expressed inclination information. The estimation comes about because of the expectation to move demonstrate uncover that vehicle factors are critical, with increments in fly out time to work, head out expenses to work and travel expenses to general stores all related with an expansion in the likelihood of moving.

The verbal confrontation encompassing the manageability of urban zones and the need to diminish reliance upon the auto as the essential method of transportation has revived enthusiasm for the connection between availability, cost and area of proprietor possessed lodging. Generally, endeavors at evaluation have utilized hedonistic examination utilizing straight-line separate estimations to central focuses. This paper centers upon factors influencing the value structure of private property in the Belfast Urban Area, looking at the relative impact of property qualities, financial variables and the effect of availability. The model utilizes an availability list figured for each of 182 movement zones and uses exchange information for an example of 2648 private property sold amid 1996. Results demonstrate that openness is of little centrality in clarifying variety in house costs at a far-reaching scale yet at a sub-showcase level, especially in bring down pay zones, availability can be a critical impact. The examination features the significance of examination at a sub-advertise level and makes inferences in regards to the multifaceted nature of connections inside a urban region. (Ryley, T., Adair, A., Smyth, A., Cooper, J., \& McGreal, S. 2000)

This investigation (Sale, M. C. 2015) reveals insight into this issue by considering the connection between the Walmer Park Shopping Center, arranged in Nelson Mandela Bay, and encompassing private property costs. A standout among-st the most noteworthy changes in the South African retail scene in the course of recent decades is the expansion in the number and size of retail strip malls arranged in, or near, neighborhoods. To dissect the relationship property estimation procedure utilized is the epicurean value demonstrates. Information was gotten from ABSA house value record. The aftereffects of this investigation show that, on account of the Walmer Park Shopping Center, a measurably critical connection between's nearness to the shopping center and neighboring property estimations is available.

This examination (Seago, J. 2013) expects to look at discoveries on how the costs of private properties are influenced by their separation from North-gate Mall, as market analysts and researchers have created a lot of research on the different elements affecting the estimation of private properties. Significant determinants of property estimations incorporate the physical qualities of a property, the ecological and courtesy properties, and 
the money related states of the deal and, above all, the area of a property. This paper uses a hedonistic relapse model to translate the impact of North-gate Mall on the estimation of close-by lodging. The paper arranges 250 distinct houses that have been sold since 2012. An example size of 50 unique houses was looked over each geographic section to speak to the general populace of houses from inside that territory. Regardless of the impediments of the model the aftereffects of this examination give additionally support to the proposed hypothesis that negative externalities of business improvements are acknowledged in a much-confined encompassing zone. When this region is passed properties encounter positive changes to their costs and their esteems increment the nearer they are to, for this situation, the strip mall.

This paper concentrates (Beaudoin, M., Des Rosiers, F., Thériault, M., \& Lagana, A. 1996) on the impact of both vicinity and size of strip malls on the benefit of encompassing private properties. The measure of a close-by strip mall anticipated that would impact family units' inclinations emphatically. The example utilized as a part of this article is drawn from a worldwide information bank of somewhere in the range of 9,000 proprietor involved private properties executed on the region of the QUC between January 1990 and December 1991. A multi-step approach is utilized to test our exploration theories, both the general execution of the indulgent condition and the consistence of individual coefficients are surveyed. A few utilitarian structures are tried and up to 60 descriptors are utilized. While the positive effect of mall estimate on private esteems is unmistakably illustrated, this investigation presents enough experimental proof to help the non-monotonic of the value separate relationship.

\section{Chapter 03: Methodology}

\section{Research Philosophy}

\subsection{Positivism}

This research philosophy is based on positivism. As this examination sticks to the view that solitary "genuine" learning expanded with recognition (the resources), compromising of estimation, is tried and true. In this examination the investigator obligations are constrained to data social event and illustration through target approach and the examination revelations are normally noticeable and quantifiable. Data gathering process is highly structured and the respondents are based on large sample size. Positivism research philosophy on Impact of one stop shop on consumer buying pattern relies upon quantifiable perceptions that will prompt measurable investigation. Appropriate hypothesis is constructed to test and analyze the relationship between independent and dependent variables i.e. There is a significant positive relationship between introduction of one stop shops and Inflation, Traffic Jams and impulse buying, rising prices of neighbor society and there is a significant negative relationship between introduction of one stop shops and Survival of Small Stores and Danger to Health.

\section{Research Approaches}

\subsection{Deductive Approach}

As this examination depends on working up a hypothesis (or speculations) in perspective of existing speculation, and after that laying out an investigation method to test the hypothesis that is the reason deductive approach is gotten. Abundance of writing in this exploration can be clarified as wealth of assets were accessible however because of lack of time to finish this review not expansive example estimate is chosen and the greater part of the examination depends on existing theory.

HA: There is a positive connection between introduction of one stop shops and Inflation.

HA: There is a positive connection between introduction of one stop shops and Impulse Buying.

HA: There is a positive connection between introduction of one stop shops and Danger of Health.

HA: There is a positive connection between introduction of one stop shops and Traffic Jams.

HA: There is a positive connection between introduction of one stop shops and Survival of Small Stores.

HA: There is a positive connection between introduction of one stop shops and rising prices of neighbor society.

\subsection{Quantitative Approach}

This examination depends on quantitative information. It holds different recognized verifiable standards for the authenticity of the approach, for instance, the number of respondents that are required to develop a quantifiably immense result. It is used to look into a broad assortment of social marvels, including feelings and subjective points of view. The quantitative approach used here as a result of broad number of respondents open, as significant measure of data can be effectively measured using quantitative frameworks, and where genuine procedures for examination can be used.

\section{Research Strategy}

This exploration is done using survey approach as it is a quantitative research venture and connected with deductive approach. It includes examining an agent extent of the populace. This overview produces quantitative information that can be examined experimentally. This methodology is most regularly used to look at causative factors between various sorts of information. As survey enables the pro to assemble massive measure of data 
from a sizeable target people and are proposed to give a 'review of how things are at a specific time'. This approach makes a great deal of data in a short traverse for a truly negligible exertion. The examination produces data in perspective of genuine discernments (exploratory data). The broadness of extent of numerous people or events suggests that it is more likely than some unique approaches to manage obtain data in perspective of a delegate test, and can in this way be generalizable to masses. Information is gathered in an institutionalized shape by methods for a poll. The questions included in questionnaire were design in the way to understand the behavior of consumer on introduction of large super marts, how they are influenced to buy unplanned items, as if large stores are becoming the reason for the downfall of small stores, and their rising development is increasing the property prices, congestions on the road and health problems, or inflation is arising due to all these situations in the economy.

\section{Choices}

\subsection{Mono Method}

In this research only one method is used for data collection i.e. quantitative method. Quantitative information gives data about amounts; i.e. data that can be measured and recorded with numbers.

\section{Time Horizon}

\subsection{Cross-sectional Time Horizon}

Data is gathered through cross-sectional time horizon, over a period of month in order to analyze the relationship among variables. Cross-sectional research inspects rely upon recognitions that occur in different social affairs at one time. This infers there is no exploratory strategy, so no components are controlled by the researcher. Instead of playing out an investigation, we would simply record the information that we find in the social occasions we are taking a gander at. This system is used to collect information in a manner of speaking. The information may then be used to make diverse methodologies to investigate the relationship that is viewed.

\section{Data Collection and Analysis 10.1. Primary Data}

Primary data has been gathered through questionnaires. Both hardcopy and online survey forms were conducted. More than 250 questionnaires were distributed among the people who use one stop shops for shopping and who has experienced shopping at large stores, either their usage rate is light, medium or heavy, of all age group, family size, both genders and of all income levels. No separate demographic profile was collected. All the respondents were the residents of Pakistan. The reason to choose only one country was time limitation for conducted the survey and also the inconvenience of reaching respondents beyond the boundary wall of Pakistan. To analyze and measure the after effects of introduction of one stops shops on consumer buying pattern 26 questions were included in questionnaire. There were 7 variables selected, Independent variable (Rising trend of one stops shops) and dependent variables (Impulse buying, Survival of small stores, rising prices of neighborhood property, Inflation, Traffic Jams and Danger to health). 3-4 questions for each variable were included in the survey form. Questionnaire was design on Likert scale, rating scale was given with 5 options ranging from strongly agree with code 1 to strongly disagree with code 5 , for each variable question.

Online survey forms were filled through Facebook, LinkedIn and via email and offline questionnaires were filled through personal visiting and distribution in hardcopy.

The number of questionnaires distributed through hard copy were 100 and through soft copy were uncountable (depend on how my many people received it). Filled 223 questionnaires were received in which 207 questionnaires were in usable form and from 205 questionnaires, 5 questionnaires were discarded due to some reason and at the end the final numbers of questionnaires remain for analysis were 200 .

\begin{tabular}{|c|c|}
\hline \multicolumn{2}{|c|}{ Statistics of Questionnaire } \\
\hline Distributed & $\begin{array}{c}\text { Hard copy=100 } \\
\text { Soft Copy= uncountable }\end{array}$ \\
\hline Received & $\mathbf{2 2 3}$ \\
\hline Usable form & $\mathbf{2 0 7}$ \\
\hline Discarded for some reason & $(7)$ \\
\hline Final no. for analysis & $\mathbf{2 0 0}$ \\
\hline
\end{tabular}

\subsection{Secondary Data}

Secondary data was gathered for literature review through research articles, thesis, journals, news, internet, magazines etc. The reason to gather other analyst work and experiments was to get better understanding of the variables with logic. It makes the research reliable and valid. 


\section{Research Design}

The investigation here is explanatory in nature as in the proposed speculation we will be explaining whether the theory that we set are legitimate or not. The sort of examination conducted here is correlational investigation i.e. regardless of whether an expansion or abatement in one variable relates to an increment or reduction in the other variable. The data we have gathered by filling up online survey forms and from hard copies by personally visiting to the respondents will now be put in to the SPSS software to reach the conclusion that whether the propose hypothesis stated in this research is accepted or rejected. After analyzing the results, the effect of one variable over other will be explained.

Here, we will discover in the case of rising pattern of shopping at one stop shops expands Inflation? Acquainting stores will lead with congested roads because of stopping issues? Substantial markets are diminishing the survival likelihood of little stores? Selling of processed packaged frozen food in one stop shops reducing the nutrient content leading health under threat? Items in basic need thing will prompt motivation purchasing? Whether Opening of large Supermarkets, grocery stores, hypermarkets etc. are increasing the prices of neighbor society?

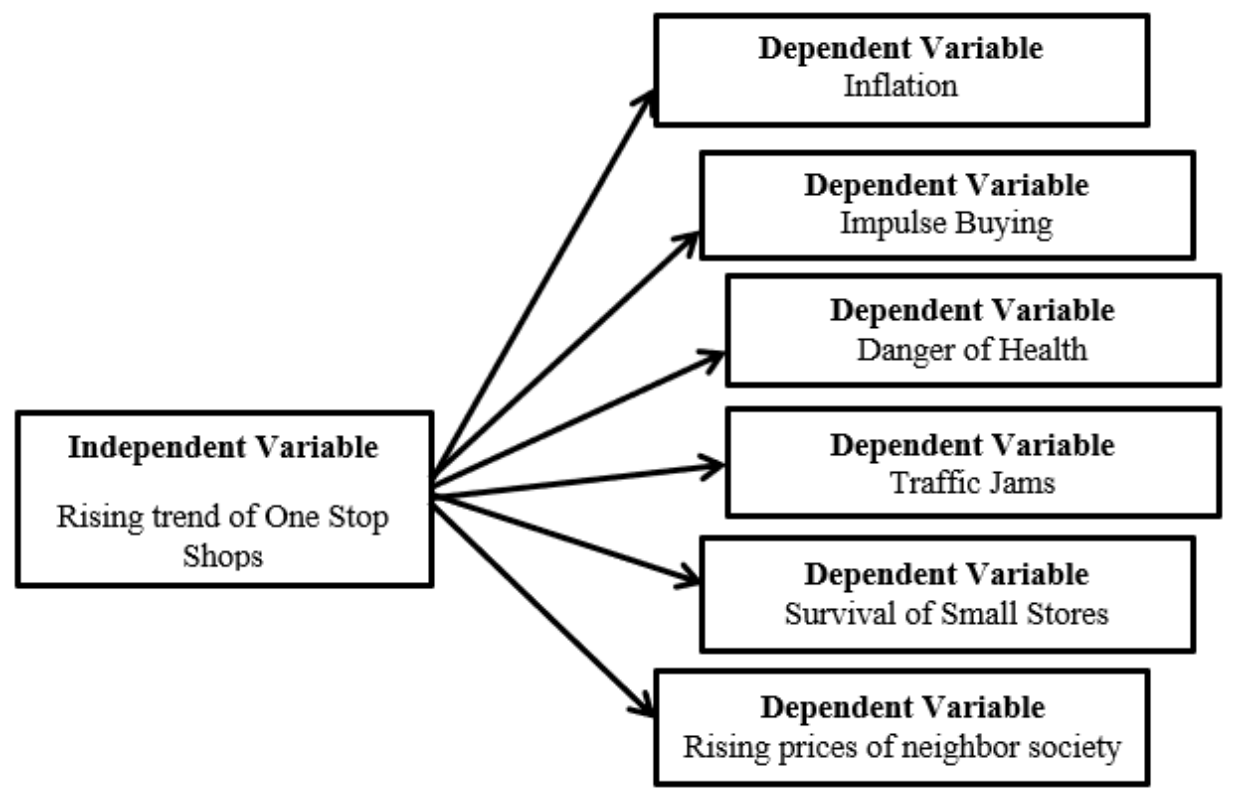

\section{Samples}

\subsection{Sample Size}

The overall area target was one country i.e. Pakistan. The sample size selected from overall population was $\mathrm{n}=200$. Large sample size helps in getting reliable result. This is a quantitative research in which size of the sample matters in determining valid and reliable results. It is a critical element of any experimental investigation in which the objective is to make surmising's about a populace from a sample.

\subsection{Sampling Techniques}

\subsubsection{Non-Probability}

For selecting the appropriate sample size from a large population for the study, sampling technique used here is non-probability sampling. It does not give every respondent/ individual equal chance of being selected because selecting individuals at random may make the results skewed.

In an exploration, certified self-assertive reviewing is always difficult to achieve. Nearly all masters are restricted by juncture, trade and workforce and out light of these obstacles, it is for all intents and purposes hard to arbitrarily test the entire masses and it is frequently vital to use another analyzing framework, the nonprobability investigating procedure.

Alternately with probability looking at, non-probability test isn't an aftereffect of a randomized assurance frames. Subjects in a non-probability test are regularly picked on the introduce of their receptiveness or by the purposive individual judgment of the expert.

So, in non-probability sampling we will be choosing our respondents according to our convenience. Depending on the time limitation and the portals through which our survey is going to take place. 


\section{Conclusion}

This research philosophy is based on positivism, deductive approach. In this research only one method is used for data collection i.e. quantitative method. Appropriate hypothesis is constructed to test and analyze the relationship between independent and dependent variables i.e. There is a significant positive relationship between introduction of one stop shops and Inflation, Traffic Jams and impulse buying, rising prices of neighbor society and there is a significant negative relationship between introduction of one stop shops and Survival of Small Stores and Danger to Health. The investigation here is explanatory in nature as in the proposed speculation we will be explaining whether the theory that we set are legitimate or not. Secondary data was gathered for literature review through research articles, thesis, journals, news, internet, magazines etc. In research strategy survey approach is adopted as in this primary data will be collected in structured way through questionnaires and the respondents are based on large sample size. Data is gathered through cross-sectional time horizon, over a period of month. For selecting the appropriate sample size from a large population for the study, sampling technique used here is non-probability sampling. It does not give every respondent/ individual equal chance of being selected. So, in non-probability sampling we will be choosing our respondents according to our convenience. Depending on the time limitation and the portals through which our survey is going to take place. The overall area target was one country i.e. Pakistan. The sample size selected from overall population was $n=200$. Primary data gathered here through questionnaires is based on both hardcopy and online survey forms were conducted, either their usage rate is light, medium or heavy, of all age group, family size, both genders and of all income levels. No separate demographic profile was collected. All the respondents were the residents of Pakistan. More than 250 questionnaires were distributed and at the end the final numbers of questionnaires remain for analysis were 200 . The data we have gathered by filling up online survey forms and from hard copies by personally visiting to the respondents will now be put in to the SPSS software to reach the conclusion that whether the propose hypothesis stated in this research is accepted or rejected. After analyzing the results, the effect of one variable over other will be explained.

\section{Chapter 04: Data Analysis}

\section{Descriptive Statistics}

Descriptive Statistics

\begin{tabular}{|c|c|c|c|c|c|c|c|}
\hline & $\mathrm{N}$ & Minimum & Maximum & Mean & Std. Deviation & \multicolumn{2}{|c|}{ Skewness } \\
\hline & Statistic & Statistic & Statistic & Statistic & Statistic & Statistic & $\begin{array}{l}\text { Std. } \\
\text { Error }\end{array}$ \\
\hline Discounts and Offers & 200 & 1 & 5 & 1.93 & .883 & .891 & .172 \\
\hline Open Display & 200 & 1 & 5 & 1.56 & .720 & 1.621 & .172 \\
\hline Saves time & 200 & 1 & 5 & 1.58 & .882 & 1.921 & .172 \\
\hline Shop for standard & 200 & 1 & 5 & 1.91 & .968 & .854 & .172 \\
\hline Unplanned Shopping & 200 & 1 & 5 & 1.59 & .869 & 1.725 & .172 \\
\hline Save less money & 200 & 1 & 5 & 2.03 & 1.029 & .731 & .172 \\
\hline Provide Convenience & 200 & 1 & 5 & 1.87 & .879 & 1.232 & .172 \\
\hline Scheme attracts people & 200 & 1 & 5 & 1.74 & .845 & 1.322 & .172 \\
\hline Impulse Buying & 200 & 1 & 5 & 1.83 & .869 & .941 & .172 \\
\hline Window display & 200 & 1 & 5 & 1.82 & .932 & 1.297 & .172 \\
\hline Unplanned Purchase & 200 & 1 & 4 & 1.69 & .921 & 1.280 & .172 \\
\hline Taste Appearance & 200 & 1 & 5 & 2.09 & 1.008 & .649 & .172 \\
\hline Easy to prepare & 200 & 1 & 5 & 2.10 & 1.051 & .951 & .172 \\
\hline Longer shelf life & 200 & 1 & 5 & 2.16 & 1.154 & .813 & .172 \\
\hline Nutritional Value & 200 & 1 & 5 & 1.76 & .983 & 1.363 & .172 \\
\hline Prefer Personal Vehicle & 200 & 1 & 5 & 1.78 & 1.010 & 1.411 & .172 \\
\hline Improper Parking & 200 & 1 & 5 & 1.38 & .734 & 2.326 & .172 \\
\hline Parking spot near mart & 200 & 1 & 5 & 1.45 & .794 & 2.233 & .172 \\
\hline Traffic due to mart & 200 & 1 & 5 & 1.69 & .910 & 1.544 & .172 \\
\hline ATM Credit cards & 200 & 1 & 5 & 1.63 & .785 & 1.451 & .172 \\
\hline Monthly Grocery & 200 & 1 & 5 & 2.11 & 1.139 & .657 & .172 \\
\hline Quick Checkout & 200 & 1 & 5 & 1.82 & .967 & 1.254 & .172 \\
\hline Comfortable Environment & 200 & 1 & 5 & 1.68 & .824 & 1.297 & .172 \\
\hline Marts increase land prices & 200 & 1 & 5 & 1.81 & .904 & 1.250 & .172 \\
\hline People reside near mart & 200 & 1 & 5 & 1.98 & 1.096 & 1.022 & .172 \\
\hline Willing to pay Premium & 200 & 1 & 5 & 2.36 & 1.240 & .577 & .172 \\
\hline Valid N (list wise) & 200 & & & & & & \\
\hline
\end{tabular}


15. Hypothesis 01: Inflation

HO: There is no relationship between introduction of one stop shops and Inflation.

HA: There is a positive connection between introduction of one stop shops and Inflation.

\begin{tabular}{|l|c|c|}
\hline \multirow{2}{*}{ Reliability } & Cronbach's Alpha & 0.885 \\
\cline { 2 - 3 } \multirow{2}{*}{ Model Summary } & N (Respondents) & 200 \\
\hline \multirow{2}{*}{ Anova } & R & $0.535^{\mathrm{a}}$ \\
\cline { 2 - 3 } & R Square & 0.286 \\
\hline \multirow{2}{*}{ Regression } & F & 79.201 \\
\hline Collinearity & Sig Value & $000^{\mathrm{a}}$ \\
\hline Correlation & B (Constant) & 0.723 \\
\cline { 2 - 3 } & Significant at the 0.01 level (2-tailed). & 0.636 \\
\hline
\end{tabular}

\subsection{Model Summary}

The value $\mathrm{R}=0.535$, indicates that there is a great deal of variance shared by the independent variables and the dependent variables.

The value R-Square $=0.286$, indicates that $28 \%$ of the variance in the dependent variable is explained by the independent variables in the model.

\subsection{Anova}

F. Sig $=79.201(0.000) \leq \alpha(0.05)$

Ho rejected

HA accepted

\subsection{Regression}

$\mathrm{IF}=\mathrm{C}+\mathrm{TOS} \beta+\mathrm{e}$

$\mathrm{IF}=0.723+0.636 \beta+\mathrm{e}$

Unstandardized coefficient for increasing trend of one stop shop is 0.636 , which indicates to us that as the trend for one stop shop increases, a 0.636 unit/points increase in inflation is predicted.

\subsection{Correlation}

There is a statistically significant $(p<.001)$ positive correlation coefficient $(0.535)$ for the association between Increasing trend of one stop shop and inflation, indicating that the linear relationship between these two variables such that the more the trend of one stop shops increases; the greater the economy will face inflation.

\section{Hypothesis 02: Increase in Impulse Buying}

HO: There is no relationship between introduction of one stop shops and Impulse Buying.

HA: There is a positive connection between introduction of one stop shops and Impulse Buying

\begin{tabular}{|l|c|c|}
\hline \multirow{2}{*}{ Reliability } & Cronbach's Alpha & 0.885 \\
\cline { 2 - 3 } \multirow{2}{*}{ Model Summary } & N (Respondents) & 200 \\
\hline \multirow{2}{*}{ Anova } & R & $0.492^{\mathrm{a}}$ \\
\cline { 2 - 3 } & R Square & 0.242 \\
\hline \multirow{2}{*}{ Regression } & F & 63.104 \\
\hline & Sig Value & $0.000^{\mathrm{a}}$ \\
\hline Collinearity & B (Constant) & 0.785 \\
\hline Correlation & B (Increasing Trend of One stop shop) & 0.566 \\
\cline { 2 - 3 } & VIF & 1.000 \\
\hline
\end{tabular}

\subsection{Model Summary}

The value $\mathrm{R}=0.492$, indicates that there is a great deal of variance shared by the independent variables and the dependent variables.

The value R-Square $=0.242$, indicates that $24 \%$ of the variance in the dependent variable is explained by the independent variables in the model.

16.2. Anova

F. Sig $=63.104(0.000) \leq \alpha(0.05)$ 
Ho rejected

HA accepted

\subsection{Regression}

$\mathrm{IM}=\mathrm{C}+\mathrm{TOS} \beta+\mathrm{e}$

$\mathrm{IM}=0.785+0.566 \beta+\mathrm{e}$

Unstandardized coefficient for increasing trend of one stop shop is 0.566 , which indicates to us that as the trend for one stop shop increases, a 0.566 unit/points increase in impulse buying is predicted.

\subsection{Correlation}

There is a statistically significant $(p<.001)$ positive correlation coefficient $(0.492)$ for the association between Increasing trend of one stop shop and impulse buying, indicating that the linear relationship between these two variables such that the more the trend of one stop shops increases; the greater the consumer are attracted towards impulse buying.

\section{Hypothesis 03: Danger to Health}

HO: There is no relationship between introduction of one stop shops and Danger to Health.

HA: There is positive connection between introduction of one stop shops and Danger to Health.

\begin{tabular}{|l|c|c|}
\hline \multirow{2}{*}{ Reliability } & Cronbach's Alpha & 0.885 \\
\cline { 2 - 3 } & N (Respondents) & 200 \\
\hline \multirow{2}{*}{ Model Summary } & R & $0.433^{\mathrm{a}}$ \\
\hline \multirow{2}{*}{ Anova } & R Square & 0.187 \\
\hline \multirow{2}{*}{ Regression } & F & 45.590 \\
\cline { 2 - 3 } & Sig Value & $0.000^{\mathrm{a}}$ \\
\hline Collinearity & B (Constant) & 1.056 \\
\hline Correlation & B (Increasing Trend of One stop shop) & 0.557 \\
\cline { 2 - 3 } & VIF & 1.000 \\
\hline
\end{tabular}

\subsection{Model Summary}

The value $\mathrm{R}=0.433$, indicates that there is a great deal of variance shared by the independent variables and the dependent variables.

The value $\mathrm{R}$-Square $=0.187$, indicates that $18.7 \%$ of the variance in the dependent variable is explained by the independent variables in the model.

\subsection{Anova}

F. Sig $=45.590(0.000) \leq \alpha(0.05)$

Ho rejected

HA accepted

\subsection{Regression}

$\mathrm{DH}=\mathrm{C}+\mathrm{TOS} \beta+\mathrm{e}$

$\mathrm{DH}=1.056+0.557 \beta+\mathrm{e}$

Unstandardized coefficient for increasing trend of one stop shop is 0.557 , which indicates to us that as the trend for one stop shop increases, a 0.557 unit/points increase in danger to health is predicted.

\subsection{Correlation}

There is a statistically significant $(p<.001)$ positive correlation coefficient $(0.433)$ for the association between Increasing trend of one stop shop and Danger to Health, indicating that the linear relationship between these two variables such that the more the trend of one stop shops increases; the greater the will be the impact on health. 
18. Hypothesis 04: Traffic Jam

HO: There is no relationship between introduction of one stop shops and Traffic Jams.

HA: There is a positive connection between introduction of one stop shops and Traffic Jams

\begin{tabular}{|l|c|c|}
\hline \multirow{2}{*}{ Reliability } & Cronbach's Alpha & 0.885 \\
\cline { 2 - 3 } \multirow{2}{*}{ Model Summary } & N (Respondents) & 200 \\
\hline \multirow{2}{*}{ Anova } & R & $0.573^{\mathrm{a}}$ \\
\cline { 2 - 3 } & R Square & 0.328 \\
\hline \multirow{2}{*}{ Regression } & F & 96.851 \\
\cline { 2 - 3 } & Sig Value & $0.000^{\mathrm{a}}$ \\
\hline Collinearity & B (Constant) & 0.501 \\
\hline Correlation & B (Increasing Trend of One stop shop) & 0.616 \\
\cline { 2 - 3 } & Significant at the 0.01 level (2-tailed). & 1.000 \\
\hline
\end{tabular}

\subsection{Model Summary}

The value $\mathrm{R}=0.573$, indicates that there is a great deal of variance shared by the independent variables and the dependent variables.

The value R-Square $=0.328$, indicates that $32 \%$ of the variance in the dependent variable is explained by the independent variables in the model.

\subsection{Anova}

F. Sig $=96.851(0.000) \leq \alpha(0.05)$

Ho rejected

HA accepted

\subsection{Regression \\ $\mathrm{TF}=\mathrm{C}+\mathrm{TOS} \beta+\mathrm{e}$ \\ $\mathrm{TF}=0.501+0.616 \beta+\mathrm{e}$}

Unstandardized coefficient for increasing trend of one stop shop is 0.616 , which indicates to us that as the trend for one stop shop increases, a 0.616 unit/points increase in Traffic Jams is predicted.

\subsection{Correlation}

There is a statistically significant $(p<.001)$ positive correlation coefficient $(0.573)$ for the association between Increasing trend of one stop shop and Traffic Jams, indicating that the linear relationship between these two variables such that the more the trend of one stop shops increases; the greater the probability of increasing Traffic Jams.

\section{Hypothesis 05: Survival of Small stores}

HO: There is no relationship between introduction of one stop shops and Survival of Small Stores.

HA: There is a positive connection between introduction of one stop shops and Survival of Small Stores.

\begin{tabular}{|l|c|c|}
\hline \multirow{2}{*}{ Reliability } & Cronbach's Alpha & 0.885 \\
\cline { 2 - 3 } \multirow{2}{*}{ Model Summary } & N (Respondents) & 200 \\
\hline \multirow{2}{*}{ Anova } & R & $0.556^{\mathrm{a}}$ \\
\cline { 2 - 3 } Regression & R Square & 0.309 \\
\cline { 2 - 3 } & F & 88.473 \\
\hline Collinearity & Sig Value & $0.000^{\mathrm{a}}$ \\
\hline Correlation & B (Constant) & 0.652 \\
\cline { 2 - 3 } & B (Increasing Trend of One stop shop) & 0.665 \\
\hline
\end{tabular}

\subsection{Model Summary}

The value $\mathrm{R}=0.556$, indicates that there is a great deal of variance shared by the independent variables and the dependent variables.

The value R-Square $=0.309$, indicates that $30 \%$ of the variance in the dependent variable is explained by the independent variables in the model. 
19.2. Anova

F. Sig $=88.473(0.000) \leq \alpha(0.05)$

Ho rejected

HA accepted

\subsection{Regression}

$\mathrm{SOS}=\mathrm{C}+\mathrm{TOS} \beta+\mathrm{e}$

$\mathrm{SOS}=0.652+0.665 \beta+\mathrm{e}$

Unstandardized coefficient for increasing trend of one stop shop is 0.665 , which indicates to us that as the trend for one stop shop increases, a 0.665 unit/points increase in difficulty for survival of small stores is predicted.

\subsection{Correlation}

There is a statistically significant $(p<.001)$ positive correlation coefficient $(0.556)$ for the association between Increasing trend of one stop shop and survival of small stores, indicating that the linear relationship between these two variables such that the more the trend of one stop shops increases; the greater the increase in difficulty for survival of small stores.

\section{Hypothesis 06: Rising prices of neighbor society}

HO: There is no relationship between introduction of one stop shops and rising prices of neighbor society. HA: There is a positive connection between introduction of one stop shops and rising prices of neighbor society

\begin{tabular}{|l|c|c|}
\hline \multirow{2}{*}{ Reliability } & Cronbach's Alpha & 0.885 \\
\cline { 2 - 3 } \multirow{2}{*}{ Model Summary } & N (Respondents) & 200 \\
\hline \multirow{2}{*}{ Anova } & R & $0.579^{\mathrm{a}}$ \\
\cline { 2 - 3 } & R Square & 0.335 \\
\hline \multirow{2}{*}{ Regression } & F & 99.748 \\
\cline { 2 - 3 } & Sig Value & $0.000^{\mathrm{a}}$ \\
\hline Collinearity & B (Constant) & 0.461 \\
\hline Correlation & B (Increasing Trend of One stop shop) & 0.910 \\
\cline { 2 - 3 } & VIF & 1.000 \\
\hline
\end{tabular}

\subsection{Model Summary}

The value $\mathrm{R}=0.579$, indicates that there is a great deal of variance shared by the independent variables and the dependent variables.

The value R-Square $=0.335$, indicates that $33 \%$ of the variance in the dependent variable is explained by the independent variables in the model.

\subsection{Anova}

F. Sig $=99.748(0.000) \leq \alpha(0.05)$

Ho rejected

HA accepted

\subsection{Regression}

$\mathrm{INP}=\mathrm{C}+\mathrm{TOS} \beta+\mathrm{e}$

$\mathrm{INP}=0.461+0.910 \beta+\mathrm{e}$

Unstandardized coefficient for increasing trend of one stop shop is 0.910 , which indicates to us that as the trend for one stop shop increases, a 0.910 unit/points increase in Neighborhood property prices are predicted.

\subsection{Correlation}

There is a statistically significant $(p<.001)$ positive correlation coefficient $(0.579)$ for the association between Increasing trend of one stop shop and Increasing neighborhood property prices, indicating that the linear relationship between these two variables such that the more the trend of one stop shops increases; the greater the rise in neighborhood property prices. 


\section{Chapter 05: Conclusion}

\section{Findings and Discussions}

\subsection{Inflation}

One stop shops and inflation are directly related to each other. Sig value below 0.05 proves the positive connection between these two variables as more the trend of one stop shops increases; the greater the economy is expected to face inflation.

Expansion is caused by the general augmentation looked for after for stock and ventures, which presents their expenses. This theory can be plot as "an abundance of money seeking after unnecessarily couple of items". Toward the day's end, if ask for is ending up speedier than supply, expenses will increase. This for the most part happens in quickly developing economies, examined by (Hayes, A.).

\subsection{Impulse Buying Behavior}

Sig value below 0.05 proves that there is positive connection between introduction of one stop shops and Impulse Buying, as more the trend of one stop shops increases; the greater the consumer is attracted towards impulse buying that's why large marts are utilizing their store design to boost incomes through Impulse purchases

Different factors such as Limited time devices, shopping condition, sexual orientation, and peevishness have real effect on drive purchasing conduct while purchasing goods at marts, proved by (Hadjali, Salimi, Nazari, and Ardestani, 2012) in their research report

(Lodhi, M. J. S.) also proved that outside and inner variables have a greater impact on buyer motivation purchasing conduct at one stop shops in Karachi. SPSS software was utilized for information investigation. Results proved the hypothesis that visual marketing and hedonistic inspiration and shopping condition have a vital pretend for buyer's drive purchasing.

\subsection{Danger of Health}

The more the trend of one stop shops increases; the greater the will be the impact on health and environment. Results showing sig value below 0.05 proved that there is a positive connection between introduction of one stop shops and Danger to Health and environment.

(Morland, K., Wing, S., and Roux, A. V. D. 2006) also in their examination also proved this variable that attributes of neighborhood sustenance conditions may assume a part in the counteractive action of overweight and weight. The accessibility of supermarkets and accommodation stores is related with an expanded pervasiveness of overweight and weight among inhabitants.

\subsection{Traffic jams}

Colossal car influxes are mainly seen in the zone after the outlets/grocery stores opening (one stop shops). Suburbanites were left stranded in the gridlock for quite a long time, leaving activity police powerless in clearing growl ups. The market is somewhat a bane for suburbanites as the excursion of a couple of minutes takes a few hours which tests their understanding under the singing sun. There is a positive connection between these two variables as the more the trend of one stop shops increases; the greater the probability of increasing Traffic Jams. Sig value below 0.05 proved this hypothesis.

(Matin, F., Herani, G. M., and Warraich, U. A. 2012) in their research also proved that development of new building, strip malls, Less stopping offices, Impact Road Design, Encroachment on street and Footpad, Movement Signals and roundabouts, Inefficiency of development police, more vehicles on road, Violation of action oversees by drivers and Political and other fomentation are the key issues for car influxes.

\subsection{Survival of Small Stores}

There lies a positive connection between introduction of one stop shops and Survival of Small Stores, sig value below 0.05 proved the hypothesis that more the trend of one stop shops increases; the greater the increase in difficulty for survival of small stores.

This quantitative research which incorporates the Positivist worldview (Jaliawala, M. M. 2014) examined that the approach of marked basic supply affixes has constrained clients to change from customary supermarkets to marked basic need chains or month to month basic need buy. The exploration examine uncovers that the 3 autonomous factors that are Proximity, Environment and Engagement are associated with channel exchanging with closeness having a low relationship.

(Ozcan, G. B. 2000) overview was intended to research the survival systems of little and medium retailers in Ankara, the second biggest city of Turkey. This research also proved that the retail spaces made by the controlled conditions of shopping centers and hypermarkets have made shopping a relaxation action and enabled Turkish ladies to be more portable. 


\subsection{Rising Property Prices}

As proved in our research a positive connection between introduction of one stop shops and rising prices of neighbor society, the more the trend of one stop shops increases; the greater the rise in neighborhood property prices

(Addae-Dapaah, K., and Lan, Y. S. 2010, January) also proved that the private properties close to a town focus with a shopping center charge huge price than those almost a town focus without a shopping center.

(Preston, J., Pagliara, F., and Kim, J. H. 2005) also evince the fact that vehicle factors are critical, with increments in fly out time to work, head out expenses to work and travel expenses to general stores all related with an expansion in the likelihood of moving.

\section{Conclusion}

As all the above findings proves that rising trend of one stop shops have a significant positive impact on economy and consumer buying pattern. All the alternative hypothesis of 6 variables (Inflation, Impulse buying, Danger to health, Traffic Jams, Survival of small stores and rising property prices) was accepted. It is a direct result of the development of grocery stores that nearby shops have shut. Purchasers just pick or select the accessible great in suspected that might be on the off chance that they can avail those in general store; they won't get it in neighborhood shops in addition. That puts small shops and more dependable alternative stores insolvent, also proved by (Jaliawala, M. M. 2014). Unlike small stores large marts are established in wide open areas or main roads influencing shoppers to use personal vehicles for monthly shopping, but inappropriate parking facilities has made the traffic jams, also examined by (Matin, F., Herani, G. M., and Warraich, U. A. 2012). Colossal car influxes were seen in the zone after the outlets/grocery stores opening. Suburbanites were left stranded in the gridlock for quite a long time, leaving activity police powerless in clearing growl ups. The market is somewhat a bane for suburbanites as the excursion of a couple of minutes takes a few hours which tests their understanding under the singing sun. Due to calm environment and availability of all items at one place people choose to buy monthly groceries at mart and as marts provide a wide area with other activities and kids favorite items people usually visit with families. If we see form the eye of consumer, amount charged have the capability to influence unintentionally to give up and purchase that item. This explanation is agreeable with (Ahtola's, 1984). Good promotional scheme, window display, shopping environment etc. these entire factors influence consumer for unplanned and impulse purchase, also analyzed by (Lodhi, M. J. S.). Grocery stores, to keep their items fresh for longer period of time need to process their food supply which is notable for having unfavorable effect on our health prompting heart issues, higher danger of malignancy, more inclined to illnesses and additionally basically not getting as much sustenance out of what we eat but still people buy them as they are easy to prepare and store (due long shelf life/ expiry date) , also researched by (Morland, K., Wing, S., and Roux, A. V. D. 2006). Supermarkets mostly follow packaging or discounting strategies often called pricing strategies which attract Individuals/ consumers to spend more than they save every month pushing economy towards inflation, as also proved by (Hayes, A.). Although all of these negative factors people still want to move to the range where they can accessible the best of openings for work. So, when greater part begins to move towards such ranges, a weight is based on such regions. This weight causes the ascent in the costs of property here. This marvel proceeds with; the proprietors of such properties get more certainty they contribute progressively and pull in the first run through purchasers. Thus, the economic situations turn out to be tight and general increment in the costs of land is watched, also proved by (Addae-Dapaah, K., and Lan, Y. S. 2010, January). As one stop shops also provide greater opportunities to the economy but still negative factors are so many that they surpluses the positive factors hiding opportunity that both people and government can avail through minor improvements. Steps to implement remedies should be properly taken so that economy can avail the better opportunity from one stop shops.

\section{Recommendations}

- Allocate appropriate evaluating spending plan for every class of product with legitimate usage.

- To fix fiscal strategy by presenting a time of higher loan fees to decrease purchaser and speculation spending

- To increment the amount and nature of nourishment accessible, available and reasonable to all stores consistently.

- To secure helpless populaces utilizing imaginative and financially savvy wellbeing nets connected to long haul advancement

- Encourage a difference in mentality and conduct towards more noteworthy utilization of supportable methods of public transport.

- Small market organizations may likewise offer motion picture rentals, check changing administrations and non-sustenance items to construct deals and benefits. 
- Improve little stores design

\section{Bibliography}

Yarahmadi, \& Hasti, A. K. (2011). Evaluating Effective Factors on Consumer Impulse Buying Behavior. Asian Journal of Business Management Studies, 174-181.

Raheem, Vishnu, P., \& Rizwan, A. (2013). Factors influencing impulse buying behaviour. European Journal of Scientific Research, 67-79.

Saraswat, R., \& Prakash, P. (2013). Review of Literature on Factor Affecting Impulse Buying Behavior of Consumers. 4D Journal of Technology and Science.

Park, J. E., \& Choi, E. J. (2013). Consequences of Impulse Buying Cross-Culturally: A Qualitative Study. International Journal of Software Engineering and Its Applications.

Hadjali, H. R., Salimi, M., Nazari, M., \& Ardestani, M. S. (2012). Exploring main factors affecting on impulse buying behaviors. Journal of American Science, 245-251.

Mathai, Thomas, S., \& Haridas, D. R. (2014). Personality - its impact on impulse buying behaviour among the retail customers in Kochin city. IOSR Journal of Business and Management, 48-55.

Zhou, H., \& Gu, Z. (2015). The Effect of Different Price Presentations on Consumer Impulse Buying Behavior: The Role of Anticipated Regret. American Journal of Industrial and Business Management, 5(01), 27.

Vishnu, P. A. R. M. A. R., \& Raheem, A. R. (2013). Factors Influencing Impulse Buying Behavior. European Journal of Scientific Research, 100(3), 67-79.

Hadjali, H. R., Salimi, M., Nazari, M., \& Ardestani, M. S. (2012). Exploring main factors affecting on impulse buying behaviors. Journal of American Science, 245-251.

Tirmizi, M. A., Rehman, K. U., \& Saif, M. I. (2009). An empirical study of consumer impulse buying behavior in local markets. European Journal of Scientific Research, 28(4), 522-532.

Lodhi, M. J. S. Consumer Shopping Behaviour in Relation to Factors Influencing Impulse Buying: A Case of Superstores in Karachi, Pakistan.

Nagadeepa, C., Selvi, J. T., \& Pushpa, A. (2015). Impact of Sale Promotion Techniques On Consumers' Impulse Buyıng Behaviour Towards Apparels At Bangalore. Asian Journal of Management Sciences \& Education Vol, 4, 1.

Thornton, L. E., Cameron, A. J., McNaughton, S. A., Worsley, A., \& Crawford, D. A. (2012). The availability of snack food displays that may trigger impulse purchases in Melbourne supermarkets. BMC Public Health, 12(1), 194.

Bhakat, Muruganantham, G., \& Shankar, R. (2013). A Review of Impulse Buying Behavior. International Journal of Marketing Studies

Zeithaml, V. A. (1988). Consumer perceptions of price, quality, and value: a means-end model and synthesis of evidence. The Journal of marketing, 2-22.

Krishna, A., Briesch, R., Lehmann, D. R., \& Yuan, H. (2002). A meta-analysis of the impact of price presentation on perceived savings. Journal of Retailing, 78(2), 101-118.

Mohan, G., Sivakumaran, B., \& Sharma, P. (2013). Impact of store environment on impulse buying behavior. European Journal of Marketing, 47(10), 1711-1732.

Mazhar, M., Daud, S., Arz Bhutto, S., \& Mubin, M. (2015). Impact of Product Packaging on Consumers Buying Behavior: Evidence from Karachi.

Karbasivar, A., \& Yarahmadi, H. (2011). Evaluating effective factors on consumer impulse buying behavior. Asian Journal of Business Management Studies, 2(4), 174-181.

Koirala, N., \& Aryal, S. (2015). Impulse Buying In Grocery Items.

Nagadeepa, C., Selvi, J. T., \& A, P. (2015). Impact of Sale Promotion Techniques on Consumers' Impulse Buyıng Behaviour towards Apparels at Bangalore. Asian Journal of Management Sciences \& Education.

Anonymous (June, 2005). Good Neighbours? Community impacts of supermarkets. Retrieved from https://www.foe.co.uk/sites/default/files/downloads/good_neighbours_community.pdf

Messinger, P. R., \& Narasimhan, C. (1995). Has power shifted in the grocery channel? Marketing Science, 14(2), $189-223$.

Jaliawala, M. M. (2014). Channel Switching Behavior from Traditional Grocery Stores to Branded Grocery Chains in Karachi. Journal of Independent Studies \& Research: Management \& Social Sciences \& Economics, 12(2).

Batislam, E., \& Filiztekin, A. (2011). Channel switching behavior during the modernization of grocery retailing in Turkey.

Borraz, F., Dubra, J., Ferrés, D., \& Zipitría, L. (2014). Supermarket entry and the survival of small stores. Review of Industrial Organization, 44(1), 73-93.

Yadav, R. K., Verma, M., \& Singh, S. (2016). Impact of organized retail on neighborhood kiryana stores: A case Study of Malwa region in Madhya Pradesh. World Scientific News, 46, 1. 
Batislam, E. P., \& Filiztekin, A. Impact of Channel Diversity and Economic Crisis on Retail Channel Choice.

Fox, E. J., Montgomery, A. L., \& Lodish, L. M. (2004). Consumer shopping and spending across retail formats. The Journal of Business, 77(S2), S25-S60.

Ozcan, G. B. (2000). The transformation of Turkish retailing: Survival strategies of small and medium-sized retailers. Journal of Southern Europe and the Balkans, 2(1), 105-120.

Goldman, A., Ramaswami, S., \& Krider, R. E. (2002). Barriers to the advancement of modern food retail formats theory and measurement. Journal of Retailing, 78(4), 281-295.

Farhangmehr, M., Marques, S., \& Silva, J. (2000). Consumer and retailer perceptions of hypermarkets and traditional retail stores in Portugal. Journal of Retailing and Consumer Services, 7(4), 197-206.

Goswami, P., \& Mishra, M. S. (2009). Would Indian consumers move from kirana stores to organized retailers when shopping for groceries? Asia Pacific Journal of Marketing and Logistics, 21(1), 127-143.

Bishop, Willard R., Jr. (1984), "Competitive Intelligence," Progressive Grocer (March), 19-20.

Doyle, Mona (1984), "New Ways of Measuring Value," Progressive Grocer-Value, Executive Report, 15-19.

Jacoby and Jerry C. Olson (1977), "Consumer Response to Price: An Attitudinal, Information Processing Perspective," in Moving Ahead with Attitude Research, Y. Wind and P. Greenberg, eds. Chicago: American Marketing Association, 73-86.

Sawyer and Peter Dickson (1984), "Psychological Perspectives on Consumer Response to Sales Promotion," in Research on Sales Promotion: Collected Papers, Katherine Jocz, ed. Cambridge, MA: Marketing Science Institute.

Schechter, Len (1984), "A Normative Conception of Value," Progressive Grocer, Executive Report, 12-14.

Baker, J., Parasuraman, A., Grewal, D. and Voss, G. B. (2002), "The influence of multiple store environment cues on perceived merchandise value and patronage intentions," Journal of Marketing, Vol.66 No.2, pp.120-41.

Ward, J. C., Mary J. B. and Barnes, J. (1992), "Measuring the proto typicality and meaning of retail environments," Journal of Retailing, Vol.68 No.2, pp.194-220.

Mattila, A. S. and Wirtz, J. (2001) "Congruency of scent and music as a driver of in-store evaluations and behavior", Journal of Retailing, Vol.77 No.2, pp.273-89.

Ang, S. H., Leong, S. M. and Lim, J. (1997), "The mediating influence of pleasure and arousal on layout and signage effects: Comparing more and less customized retail services," Journal of Retailing and Consumer Services, Vol.4 No.1, pp.13-24.

Sharma, A. and Stafford, T. F. (2000), "The effect of retail atmospherics on customers' perceptions of salespeople and customer persuasion: An empirical investigation," Journal of Business Research, Vol.49 No.2, pp.183-91.

Simonson, I. (1999), “The effect of product assortment on buyer preference,” Journal of Retailing, Vol.75 No.3, pp.347-70.

Dubé, L. and Morin, S. (2001), "Background music pleasure and store evaluation: Intensity effects and psychological mechanisms," Journal of Business Research, Vol. 54 No.2, pp.107- 13.

Beverland, M., Lim, E.A.C., Morrison, M. and Terziovski, M. (2006), "In-store music and consumer-brand relationships: Relational transformation following experiences of (mis) fit," Journal of Business Research, Vol.59 No.9, pp.982-89.

Summers, T. A. and Hebert, P. A. (2001), "Shedding some light on store atmospherics influence of illumination on consumer behavior," Journal of Business Research, Vol.54 No.2, pp.145-50.

Chebat, J. C. and Michon, R. (2003), "Impact of ambient odors on mall shoppers' emotions, cognition, and spending: A test of competitive causal theories," Journal of Business Research, Vol.56 No.7, pp.529-39.

S., Ayesha (October 30, 2017). What happens when customers priorities 'experience' over 'product'? Retrieved from http://aurora.dawn.com/news/1142025/.

Anonymous (May 29, 2016). Supermarket in Gulshan-e-Iqbal causes massive traffic jams. Retrieved from https://www.pakistantoday.com.pk/2016/05/29/supermarket-in-gulshan-e-iqbal-causes-massive-trafficjams/

A., Amad (July 29, 2016). Reasons behind the Shifts in Property Prices in Pakistan. Retrieved from http://rightproperty.pk/blog/reasons-behind-the-shifts-in-property-prices/

Federal Reserve Bank of St. Louis Review (July/August 2011). 93(4), pp. 223-33.

Van Dalen, G. C., \& Urban, S. (2016). Capitalization of supermarket proximity in house prices in Rotterdam.

Addae-Dapaah, K., \& Lan, Y. S. (2010, January). Shopping centers and the price of proximate residential properties. In 16th Annual Conference of the Pacific Rim Real Estate Society. Massey University: Wellington, New Zealand.

Des Rosiers, F., Lagana, A., Thériault, M., \& Beaudoin, M. (1996). Shopping centers and house values: an empirical investigation. Journal of Property Valuation and Investment, 14(4), 41-62.

Matthews, J. W. (2006). The effect of proximity to commercial uses on residential prices. 
Fossen, V. W. (2017). The Effect of Supermarket Entrance on Nearby Residential Property Values in the United States from 1997 to 2015.

Kim, J. H., Pagliara, F., \& Preston, J. (2005). The intention to move and residential location choice behavior. Urban Studies, 42(9), 1621-1636.

Larson, J. S., Bradlow, E. T., \& Fader, P. S. (2005). An exploratory look at supermarket shopping paths. International Journal of research in Marketing, 22(4), 395-414.

Yang, A., Do, B., Wang, G. L., Chang, L. Y., \& Hung, F. C. (2011). Assessing competitiveness of foreign and local supermarket chains in Vietnamese market by using Fuzzy TOPSIS method. E3 Journal of Business Management and Economics, 2(5), 209-216.

Van der Waerden, P., Borgers, A., \& Timmermans, H. (1998). The impact of the parking situation in shopping centers on store choice behavior. Geo Journal, 45(4), 309-315.

Pakistan Observer (October 21, 2017). "Supermarket opening in Gulshan area causes traffic jam". Retrieved from http://pakobserver.net/supermarket-opening-in-gulshan-area-causes-traffic-jam/

Axhausen, K. W., \& Polak, J. W. (1991). Choice of parking: stated preference approach. Transportation, 18(1), 59-81.

Hamze, Abrar. (June 2, 2016). "City super markets causing traffic chaos". Retrieved from https://dailytimes.com.pk/78465/city-super-markets-causing-traffic-chaos/

Domingo, Katrina. (September 22, 2017). "How traffic jams are re-shaping grocery shopping". ABS-CBN News. Retrieved from http://news.abs-cbn.com/business/09/22/17/how-traffic-jams-are-re-shaping-groceryshopping

Mone, J., Simon, (July, 01, 2014). "One-stop-center malls help curb city congestion”. Daily Monitor. Retrieved from http://mobile.monitor.co.ug/Oped/One-stop-centre-malls-help-curb-city-congestion/691272-2367242format-xhtml-v0bau6/index.html

Abbas, K. A. (2004). Framework for assessing traffic impacts generated by mega complexes: a case study of San Stefano grand plaza, Egypt. Impact Assessment and Project Appraisal, 22(4), 311-325.

Matin, F., Herani, G. M., \& Warraich, U. A. (2012). Factors affecting traffic jam in Karachi and its Impact on performance of economy. KASBIT Journal of Management \& Social Science, 5, 25-32.

Sivanand, Kommina, (January, 26). Why there are frequent traffic jams in India? Quora. Retrieved from https://www.quora.com/Why-there-are-frequent-traffic-jams-in-India

Timperio, A., Ball, K., Roberts, R., Campbell, K., Andrianopoulos, N., \& Crawford, D. (2008). Children's fruit and vegetable intake: associations with the neighborhood food environment. Preventive medicine, 46(4), 331-335.

Laraia, B. A., Siega-Riz, A. M., Kaufman, J. S., \& Jones, S. J. (2004). Proximity of supermarkets is positively associated with diet quality index for pregnancy. Preventive medicine, 39(5), 869-875.

Cheadle, A., Psaty, B. M., Curry, S., Wagner, E., Diehr, P., Koepsell, T., \& Kristal, A. (1991). Community-level comparisons between the grocery store environment and individual dietary practices. Preventive medicine, 20(2), 250-261.

Morland, K., Roux, A. V. D., \& Wing, S. (2006). Supermarkets, other food stores, and obesity: the atherosclerosis risk in communities study. American journal of preventive medicine, 30(4), 333-339.

Van Boxstael, S., Devlieghere, F., Berkvens, D., Vermeulen, A., \& Uyttendaele, M. (2014). Understanding and attitude regarding the shelf life labels and dates on pre-packed food products by Belgian consumers. Food Control, 37, 85-92.

Levell, P., \& Skingle, T. (2012). Comparing household inflation experiences measured by the CPI and RPI (No. W12/21). IFS Working Papers.

Griffith, R., Leibtag, E., Leicester, A., \& Nevo, A. (2009). Consumer shopping behavior: how much do consumers save? The Journal of Economic Perspectives, 23(2), 99-120.

Cavallo, A., Cruces, G., \& Perez-Truglia, R. (2014). Inflation Expectations, Learning and Supermarket Prices (No. w20576). National Bureau of Economic Research.

Buzacott, J. A. (1975). Economic order quantities with inflation. Operational research quarterly, 553-558.

Hayes, A. CFA. Inflation: What Is Inflation? Retrieved from https://www.investopedia.com/university/inflation/inflation1.asp

Adair, A., McGreal, S., Smyth, A., Cooper, J., \& Ryley, T. (2000). House prices and accessibility: The testing of relationships within the Belfast urban area. Housing studies, 15(5), 699-716.

Sale, M. C. (2015). The Impact of a Shopping Centre on the Value of Adjacent Residential Properties (No. 518).

Seago, J. (2013). Northgate Mall's effect on surrounding property values. Economics.

Des Rosiers, F., Lagana, A., Thériault, M., \& Beaudoin, M. (1996). Shopping centres and house values: an empirical investigation. Journal of Property Valuation and Investment, 14(4), 41-62.

Reardon, T., \& Berdegué, J. A. (2002). The rapid rise of supermarkets in Latin America: challenges and opportunities for development. Development policy review, 20(4), 371-388 


\section{Questionnaire}

\section{$\underline{\text { Appendix }}$}

I am the Student of BS (Marketing) final Year, Department of Commerce, Jinnah University for Women. The following Questionnaire is designed to gather information on the impact of One Stop Shop on Consumer Buying Pattern. I would be very grateful if you could fill out my questionnaire. It will take around 2 minutes, and your time will be greatly appreciated. The information you provide will be kept strictly confidential and will not be shared with any organization or third party.

\begin{tabular}{|c|c|c|c|c|c|c|}
\hline & $\begin{array}{l}\text { Please tick one option form the given } \\
\text { table }\end{array}$ & $\begin{array}{c}\text { Strongly } \\
\text { agree }\end{array}$ & Agree & Neutral & Disagree & $\begin{array}{l}\text { Strongly } \\
\text { Disagree }\end{array}$ \\
\hline $\mathbf{A}$ & Rising trend of one stop shops & & & & & \\
\hline 1 & $\begin{array}{l}\text { People shop at supermarkets because it } \\
\text { gives more discounts and offers. }\end{array}$ & & & & & \\
\hline 2 & $\begin{array}{l}\text { People prefer open display of all items, } \\
\text { rather than asking shopkeeper to } \\
\text { display some. }\end{array}$ & & & & & \\
\hline 3 & $\begin{array}{l}\text { Shopping at supermarket saves time as } \\
\text { it provides all items at one place. }\end{array}$ & & & & & \\
\hline 4 & $\begin{array}{l}\text { Super stores are increasing because } \\
\text { people shop there as a symbol of high } \\
\text { standard. }\end{array}$ & & & & & \\
\hline $\mathbf{B}$ & Inflation & & & & & \\
\hline 5 & $\begin{array}{l}\text { People normally buy some products on } \\
\text { their grocery shopping trip that they } \\
\text { hadn't planned too. }\end{array}$ & & & & & \\
\hline 6 & $\begin{array}{l}\text { Fixed price tags compel people to save } \\
\text { less money. }\end{array}$ & & & & & \\
\hline 7 & $\begin{array}{l}\text { Convenience at large supermarket is the } \\
\text { main reason for unplanned purchase. }\end{array}$ & & & & & \\
\hline $\mathbf{C}$ & Impulse Buying & & & & & \\
\hline 8 & $\begin{array}{l}\text { A good promotional scheme at } \\
\text { supermarket attracts people. }\end{array}$ & & & & & \\
\hline 9 & $\begin{array}{l}\text { Shopping environment of the store } \\
\text { affects impulse buying. }\end{array}$ & & & & & \\
\hline 10 & $\begin{array}{l}\text { Window display in a store influence } \\
\text { people for impulse purchase. }\end{array}$ & & & & & \\
\hline 11 & $\begin{array}{l}\text { I often do unplanned purchase in } \\
\text { supermarket. }\end{array}$ & & & & & \\
\hline $\mathbf{D}$ & Danger to Health & & & & & \\
\hline 12 & $\begin{array}{l}\text { Taste and Appearance of the good } \\
\text { matters, although it has been artificially } \\
\text { processed. }\end{array}$ & & & & & \\
\hline 13 & $\begin{array}{l}\text { Processed foods are considered best } \\
\text { because they are easy to prepare and } \\
\text { store. }\end{array}$ & & & & & \\
\hline 14 & $\begin{array}{l}\text { People purchase processed food } \\
\text { because of long shelf life (expiry date). }\end{array}$ & & & & & \\
\hline 15 & $\begin{array}{l}\text { Nutrition value of processed food is } \\
\text { less as compared to fresh items. }\end{array}$ & & & & & \\
\hline $\mathbf{E}$ & Traffic Jams & & & & & \\
\hline 16 & $\begin{array}{l}\text { I prefer to use personal vehicle rather } \\
\text { than public transport for shopping at } \\
\text { mart. }\end{array}$ & & & & & \\
\hline 17 & $\begin{array}{l}\text { Improper parking facility creates road } \\
\text { jams in front of supermarkets. }\end{array}$ & & & & & \\
\hline
\end{tabular}




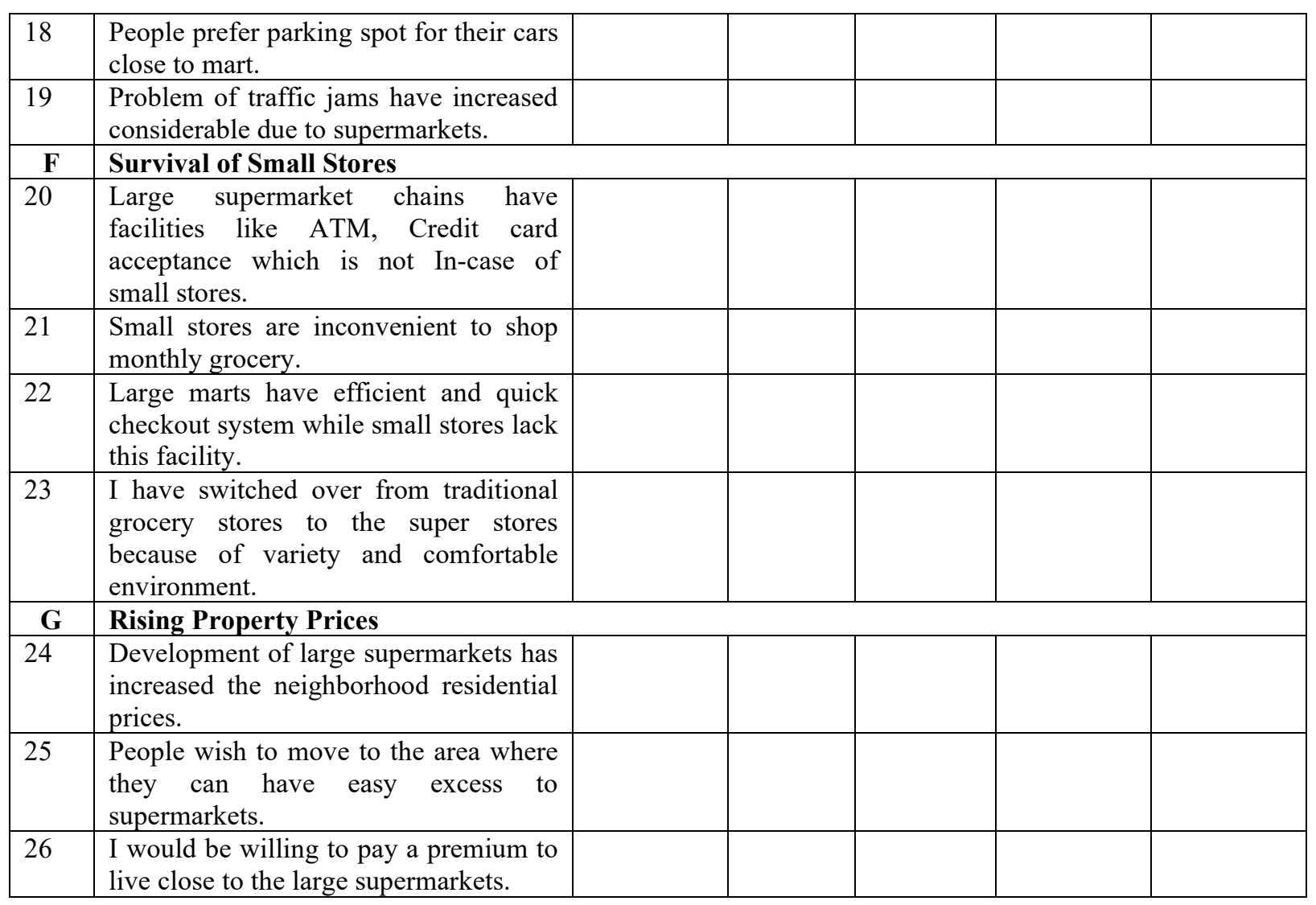

\section{Results/Tables}

Case Processing Summary

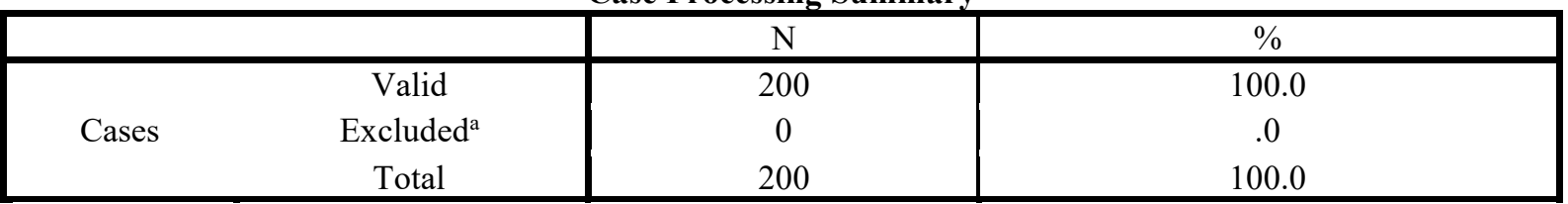

a. List wise deletion based on all variables in the procedure.

Reliability Statistics

\begin{tabular}{|c|c|}
\hline Cronbach's Alpha & N of Items \\
\hline .885 & 7 \\
\hline
\end{tabular}

\section{Inflation}

\begin{tabular}{|c|c|c|c|c|}
\hline Model & $\mathrm{R}$ & R Square & Adjusted R Square & Std. Error of the Estimate \\
\hline 1 & $.535^{\mathrm{a}}$ & .286 & .282 & .56343 \\
\hline
\end{tabular}

a. Predictors: (Constant), Increasing Trend of One stop shops

ANOVA $^{b}$

\begin{tabular}{|ll|c|c|c|c|c|}
\hline Model & & Sum of Squares & df & Mean Square & F & Sig. \\
\hline \multirow{2}{*}{1} & Regression & 25.143 & 1 & 25.143 & 79.201 & $.000^{\mathrm{a}}$ \\
& Residual & 62.857 & 198 & .317 & & \\
& Total & 87.999 & 199 & & & \\
\hline
\end{tabular}

a. Predictors: (Constant), Increasing Trend of One stop shops

b. Dependent Variable: Inflation 


\begin{tabular}{|c|c|c|c|c|c|c|c|}
\hline \multicolumn{8}{|c|}{ Coefficients $^{\mathrm{a}}$} \\
\hline \multirow{2}{*}{ Model } & \multicolumn{2}{|c|}{$\begin{array}{l}\text { Unstandardized } \\
\text { Coefficients }\end{array}$} & $\begin{array}{c}\text { Standardized } \\
\text { Coefficients }\end{array}$ & \multirow[t]{2}{*}{$\mathrm{t}$} & \multirow{2}{*}{ Sig. } & \multicolumn{2}{|c|}{ Collinearity Statistics } \\
\hline & $\mathrm{B}$ & Std. Error & Beta & & & Tolerance & VIF \\
\hline (Constant) & .723 & .131 & & 5.526 & .000 & & \\
\hline $\begin{array}{l}1 \text { Increasing Trend of } \\
\text { One stop shop }\end{array}$ & .636 & .071 & .535 & 8.899 & .000 & 1.000 & 1.000 \\
\hline
\end{tabular}

a. Dependent Variable: Inflation

\section{Correlations}

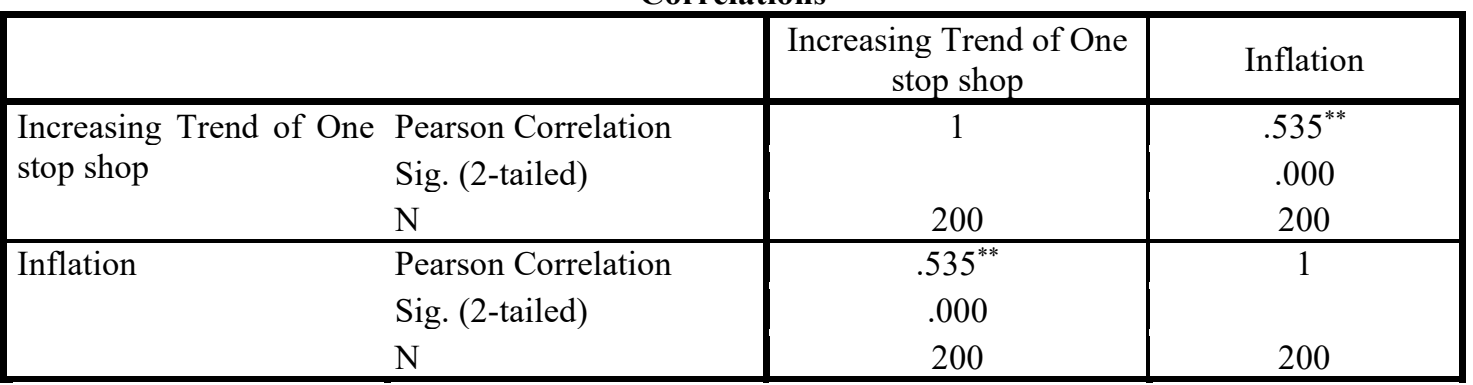

**. Correlation is significant at the 0.01 level (2-tailed).

\section{Impulse Buying}

\begin{tabular}{|l|c|c|c|c|}
\hline Model & $\mathrm{R}$ & R Square & Adjusted R Square & Std. Error of the Estimate \\
\hline 1 & $.492^{\mathrm{a}}$ & .242 & .238 & .56219 \\
\hline
\end{tabular}

a. Predictors: (Constant), Increasing Trend of One stop shops

ANOVA $^{b}$

\begin{tabular}{|c|c|c|c|c|c|}
\hline Model & Sum of Squares & $\mathrm{df}$ & Mean Square & $\mathrm{F}$ & Sig. \\
\hline $\begin{array}{ll}1 & \text { Regression } \\
& \text { Residual } \\
& \text { Total }\end{array}$ & $\begin{array}{l}19.944 \\
62.579 \\
82.524\end{array}$ & $\begin{array}{c}1 \\
198 \\
199\end{array}$ & $\begin{array}{c}19.944 \\
.316\end{array}$ & 63.104 & $.000^{\mathrm{a}}$ \\
\hline
\end{tabular}

a. Predictors: (Constant), Increasing Trend of One stop shops

b. Dependent Variable: Impulse Buying

Coefficients $^{\mathrm{a}}$

\begin{tabular}{|c|c|c|c|c|c|c|c|}
\hline \multirow[b]{2}{*}{ Model } & \multicolumn{2}{|c|}{$\begin{array}{c}\text { Unstandardized } \\
\text { Coefficients }\end{array}$} & \multirow{2}{*}{$\begin{array}{c}\text { Standardized } \\
\text { Coefficients }\end{array}$} & \multirow[t]{2}{*}{$\mathrm{t}$} & \multirow[t]{2}{*}{ Sig. } & \multicolumn{2}{|c|}{ Collinearity Statistics } \\
\hline & $\mathrm{B}$ & Std. Error & & & & Tolerance & VIF \\
\hline $1 \quad$ (Constant) & .785 & .131 & & 6.014 & .000 & & \\
\hline $\begin{array}{l}\text { Increasing Trend } \\
\text { of One stop shop }\end{array}$ & .566 & .071 & .492 & 7.944 & .000 & 1.000 & 1.000 \\
\hline
\end{tabular}

a. Dependent Variable: Impulse Buying

\section{Correlations}

\begin{tabular}{|c|c|c|}
\hline & $\begin{array}{l}\text { Increasing Trend of One } \\
\text { stop shop }\end{array}$ & Impulse Buying \\
\hline $\begin{array}{l}\begin{array}{l}\text { Increasing Trend of One } \\
\text { stop shop } \\
\end{array} \\
\text { Sig. (2-tailed) } \\
\text { N }\end{array}$ & 1 & $\begin{array}{l}.492^{* *} \\
.000 \\
200\end{array}$ \\
\hline $\begin{array}{l}\text { Pearson Correlation } \\
\text { Sig. (2-tailed) } \\
\text { N }\end{array}$ & $\begin{array}{l}.492^{* *} \\
.000 \\
200\end{array}$ & $\begin{array}{c}1 \\
200\end{array}$ \\
\hline
\end{tabular}

\footnotetext{
**. Correlation is significant at the 0.01 level (2-tailed).
} 


\section{Danger to Health}

\begin{tabular}{|l|c|c|c|c|}
\hline Model & R & R Square & Adjusted R Square & Std. Error of the Estimate \\
\hline 1 & $.433^{\mathrm{a}}$ & .187 & .183 & .65097 \\
\hline
\end{tabular}

a. Predictors: (Constant), Increasing Trend of One stop shops

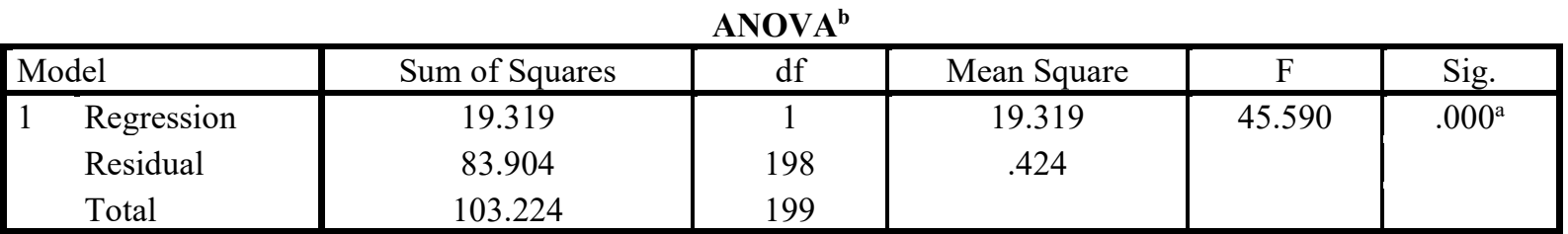

a. Predictors: (Constant), Increasing Trend of One stop shops

b. Dependent Variable: Damage to Health

Coefficients $^{\text {a }}$

\begin{tabular}{|c|c|c|c|c|c|c|c|}
\hline \multirow[b]{2}{*}{ Model } & \multicolumn{2}{|c|}{$\begin{array}{c}\text { Unstandardized } \\
\text { Coefficients }\end{array}$} & $\begin{array}{c}\text { Standardized } \\
\text { Coefficients }\end{array}$ & \multirow[b]{2}{*}{$\mathrm{t}$} & \multirow[b]{2}{*}{ Sig. } & \multicolumn{2}{|c|}{ Collinearity Statistics } \\
\hline & $\mathrm{B}$ & Std. Error & Beta & & & Tolerance & VIF \\
\hline 1 (Constant) & 1.056 & .151 & & 6.984 & .000 & & \\
\hline $\begin{array}{l}\text { Increasing Trend } \\
\text { of One stop shop }\end{array}$ & .557 & .083 & .433 & 6.752 & .000 & 1.000 & 1.000 \\
\hline
\end{tabular}

a. Dependent Variable: Damage to Health

\section{Correlations}

\begin{tabular}{|c|c|c|}
\hline & $\begin{array}{c}\text { Increasing Trend of One stop } \\
\text { shop }\end{array}$ & Damage to Health \\
\hline $\begin{array}{ll}\text { Increasing Trend } & \text { of Pearson Correlation } \\
\text { One stop shop } & \text { Sig. (2-tailed) } \\
& \mathrm{N}\end{array}$ & $\begin{array}{c}1 \\
200\end{array}$ & $\begin{array}{l}.433^{* *} \\
.000 \\
200\end{array}$ \\
\hline $\begin{array}{ll}\text { Damage to Health } & \text { Pearson Correlation } \\
& \text { Sig. (2-tailed) } \\
& \text { N }\end{array}$ & $\begin{array}{l}.433^{* *} \\
.000 \\
200\end{array}$ & $\begin{array}{c}1 \\
200\end{array}$ \\
\hline
\end{tabular}

**. Correlation is significant at the 0.01 level (2-tailed).

\section{Traffic Jams}

\begin{tabular}{|c|c|c|c|c|}
\hline & & & Model Summary & \\
\hline Model & $\mathrm{R}$ & R Square & Adjusted R Square & Std. Error of the Estimate \\
\hline 1 & $.573^{\mathrm{a}}$ & .328 & .325 & .49330 \\
\hline
\end{tabular}

a. Predictors: (Constant), Increasing Trend of One stop shops

ANOVA ${ }^{b}$

\begin{tabular}{|c|c|c|c|c|c|}
\hline Model & Sum of Squares & $\mathrm{df}$ & Mean Square & $\mathrm{F}$ & Sig. \\
\hline 1 Regression & 23.568 & 1 & 23.568 & 96.851 & $.000^{\mathrm{a}}$ \\
\hline Residual & 48.182 & 198 & .243 & & \\
\hline Total & 71.750 & 199 & & & \\
\hline
\end{tabular}

a. Predictors: (Constant), Increasing Trend of One stop shops

b. Dependent Variable: Traffic Jams 


\begin{tabular}{|c|c|c|c|c|c|c|c|}
\hline \multicolumn{8}{|c|}{ Coefficients $^{\mathrm{a}}$} \\
\hline \multirow[b]{2}{*}{ Model } & \multicolumn{2}{|c|}{$\begin{array}{c}\text { Unstandardized } \\
\text { Coefficients }\end{array}$} & \multirow{2}{*}{$\begin{array}{c}\begin{array}{c}\text { Standardized } \\
\text { Coefficients }\end{array} \\
\text { Beta }\end{array}$} & \multirow[b]{2}{*}{$\mathrm{t}$} & \multirow[b]{2}{*}{ Sig. } & \multicolumn{2}{|c|}{ Collinearity Statistics } \\
\hline & $\mathrm{B}$ & Std. Error & & & & Tolerance & VIF \\
\hline $\begin{array}{l}1 \text { (Constant) } \\
\text { Increasing } \\
\text { Trend of One } \\
\text { stop shop }\end{array}$ & $\begin{array}{l}.501 \\
.616\end{array}$ & $\begin{array}{l}.115 \\
.063\end{array}$ & .573 & $\begin{array}{l}4.378 \\
9.841\end{array}$ & $\begin{array}{l}.000 \\
.000\end{array}$ & 1.000 & 1.000 \\
\hline
\end{tabular}

a. Dependent Variable: Traffic Jams

\section{Correlations}

\begin{tabular}{|c|c|c|}
\hline & Increasing Trend of One stop shop & Traffic Jams \\
\hline $\begin{array}{lcc}\begin{array}{l}\text { Increasing } \\
\text { stop shop }\end{array} & \text { Trend of } \text { One } \begin{array}{l}\text { Pearson Correlation } \\
\text { Sig. (2-tailed) } \\
\end{array} \\
& \mathrm{N} \\
\end{array}$ & 1 & $\begin{array}{l}.573^{* *} \\
.000 \\
200\end{array}$ \\
\hline $\begin{array}{l}\text { Pearson Correlation } \\
\text { Sig. (2-tailed) } \\
\mathrm{N}\end{array}$ & $\begin{array}{l}.573^{* *} \\
.000 \\
200\end{array}$ & $\begin{array}{c}1 \\
200\end{array}$ \\
\hline
\end{tabular}

**. Correlation is significant at the 0.01 level (2-tailed).

\section{Survival of Small Stores}

\begin{tabular}{|l|c|c|c|c|}
\hline Model & R & R Square & Adjusted R Square & Std. Error of the Estimate \\
\hline 1 & $.556^{\mathrm{a}}$ & .309 & .305 & .55719 \\
\hline
\end{tabular}

a. Predictors: (Constant), Increasing Trend of One stop shops

\begin{tabular}{|c|c|c|c|c|c|}
\hline \multicolumn{6}{|c|}{ ANOVA $^{b}$} \\
\hline Model & Sum of Squares & $\mathrm{df}$ & Mean Square & $\mathrm{F}$ & Sig. \\
\hline $\begin{array}{ll}1 & \text { Regression } \\
& \text { Residual } \\
& \text { Total }\end{array}$ & $\begin{array}{l}27.467 \\
61.470 \\
88.937\end{array}$ & $\begin{array}{c}1 \\
198 \\
199\end{array}$ & $\begin{array}{c}27.467 \\
.310\end{array}$ & 88.473 & $.000^{\mathrm{a}}$ \\
\hline
\end{tabular}

a. Predictors: (Constant), Increasing Trend of One stop shops

b. Dependent Variable: Survival of Small Stores

Coefficients $^{\mathbf{a}}$

\begin{tabular}{|c|c|c|c|c|c|c|c|}
\hline \multirow[b]{2}{*}{ Model } & \multicolumn{2}{|c|}{$\begin{array}{l}\text { Unstandardized } \\
\text { Coefficients }\end{array}$} & \multirow{2}{*}{$\begin{array}{c}\begin{array}{c}\text { Standardized } \\
\text { Coefficients }\end{array} \\
\text { Beta }\end{array}$} & \multirow[b]{2}{*}{ l } & \multirow[b]{2}{*}{ Sig. } & \multicolumn{2}{|c|}{ Collinearity Statistics } \\
\hline & $\mathrm{B}$ & Std. Error & & & & Tolerance & VIF \\
\hline $\begin{array}{l}1 \text { (Constant) } \\
\text { Increasing } \\
\text { Trend of One } \\
\text { stop shop }\end{array}$ & $\begin{array}{l}.652 \\
.665\end{array}$ & $\begin{array}{l}.129 \\
.071\end{array}$ & .556 & $\begin{array}{l}5.043 \\
9.406\end{array}$ & $\begin{array}{l}.000 \\
.000\end{array}$ & 1.000 & 1.000 \\
\hline
\end{tabular}

a. Dependent Variable: Survival of Small Stores

\section{Correlations}

\begin{tabular}{|c|c|c|c|}
\hline & & $\begin{array}{l}\text { Increasing Trend of One } \\
\text { stop shop }\end{array}$ & $\begin{array}{c}\text { Survival of Small } \\
\text { Stores }\end{array}$ \\
\hline $\begin{array}{l}\text { Increasing Trend of One stop } \\
\text { shop }\end{array}$ & $\begin{array}{l}\text { Pearson Correlation } \\
\text { Sig. (2-tailed) } \\
\text { N }\end{array}$ & $\begin{array}{c}1 \\
200\end{array}$ & $\begin{array}{l}.556^{* *} \\
.000 \\
200\end{array}$ \\
\hline Survival of Small Stores & $\begin{array}{l}\text { Pearson Correlation } \\
\text { Sig. (2-tailed) } \\
\text { N }\end{array}$ & $\begin{array}{l}.556^{* *} \\
.000 \\
200\end{array}$ & $\begin{array}{c}1 \\
200\end{array}$ \\
\hline
\end{tabular}

**. Correlation is significant at the 0.01 level (2-tailed). 


\section{Rising Property Prices}

\begin{tabular}{|l|c|c|c|c|}
\hline Model & R & R Square & Adjusted R Square & Std. Error of the Estimate \\
\hline 1 & $.579^{\mathrm{a}}$ & .335 & .332 & .71816 \\
\hline
\end{tabular}

a. Predictors: (Constant), Increasing Trend of One stop shops

\begin{tabular}{|c|c|c|c|c|c|}
\hline \multicolumn{6}{|c|}{$\operatorname{ANOVA}^{b}$} \\
\hline Model & Sum of Squares & $\mathrm{df}$ & Mean Square & $\mathrm{F}$ & Sig. \\
\hline 1 Regression & 51.445 & 1 & 51.445 & 99.748 & $.000^{\mathrm{a}}$ \\
\hline Residual & 102.119 & 198 & .516 & & \\
\hline Total & 153.564 & 199 & & & \\
\hline
\end{tabular}

a. Predictors: (Constant), Increasing Trend of One stop shops

b. Dependent Variable: Rising Property Prices

Coefficients $^{\mathbf{a}}$

\begin{tabular}{|c|c|c|c|c|c|c|c|}
\hline \multirow[b]{2}{*}{ Model } & \multicolumn{2}{|c|}{$\begin{array}{l}\text { Unstandardized } \\
\text { Coefficients }\end{array}$} & \multirow{2}{*}{$\begin{array}{c}\begin{array}{c}\text { Standardized } \\
\text { Coefficients }\end{array} \\
\text { Beta }\end{array}$} & \multirow[b]{2}{*}{$\mathrm{t}$} & \multirow[b]{2}{*}{ Sig. } & \multicolumn{2}{|c|}{ Collinearity Statistics } \\
\hline & $\mathrm{B}$ & Std. Error & & & & Tolerance & VIF \\
\hline 1 (Constant) & .461 & .167 & & 2.762 & .006 & & \\
\hline $\begin{array}{l}\text { Increasing } \\
\text { Trend of One } \\
\text { stop shop }\end{array}$ & .910 & .091 & .579 & 9.987 & .000 & 1.000 & 1.000 \\
\hline
\end{tabular}

a. Dependent Variable: Rising Property Prices

\section{Correlations}

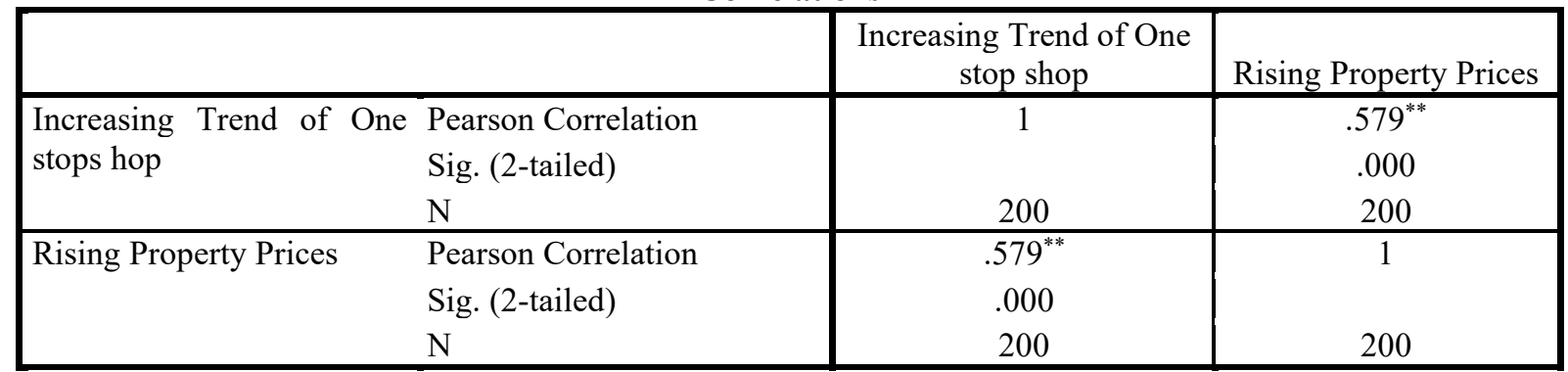

**. Correlation is significant at the 0.01 level (2-tailed). 